University of Nebraska - Lincoln

DigitalCommons@University of Nebraska - Lincoln

\title{
Impacts of insect herbivory on cactus population dynamics: experimental demography across an environmental gradient
}

\author{
Tom E. X. Miller \\ Florida State University, tom.miller@rice.edu \\ Svata M. Louda \\ University of Nebraska - Lincoln, slouda1@unl.edu \\ Karen A. Rose \\ University of Sheffield, UK \\ James O. Eckberg \\ University of Nebraska - Lincoln
}

Follow this and additional works at: https://digitalcommons.unl.edu/bioscifacpub

Part of the Life Sciences Commons

Miller, Tom E. X.; Louda, Svata M.; Rose, Karen A.; and Eckberg, James O., "Impacts of insect herbivory on cactus population dynamics: experimental demography across an environmental gradient" (2009).

Faculty Publications in the Biological Sciences. 101.

https://digitalcommons.unl.edu/bioscifacpub/101

This Article is brought to you for free and open access by the Papers in the Biological Sciences at DigitalCommons@University of Nebraska - Lincoln. It has been accepted for inclusion in Faculty Publications in the Biological Sciences by an authorized administrator of DigitalCommons@University of Nebraska - Lincoln. 


\title{
Impacts of insect herbivory on cactus population dynamics: experimental demography across an environmental gradient
}

\author{
Tom E. X. Miller, ${ }^{1,3}$ Svata M. Louda, ${ }^{1}$ Karen A. Rose, ${ }^{2}$ and James O. Eckberg ${ }^{1}$ \\ ${ }^{1}$ School of Biological Sciences, University of Nebraska, Lincoln, Nebraska 68588-0118 USA \\ ${ }^{2}$ Department of Animal and Plant Sciences, University of Sheffield, Sheffield S10 2 TN United Kingdom
}

\begin{abstract}
Understanding the role of consumers in plant population dynamics is important, both conceptually and practically. Yet, while the negative effects of herbivory on plant performance have been well documented, we know much less about how individuallevel damage translates to impacts on population growth or whether spatial variation in herbivory affects patterns of plant distribution. We studied the role of insect herbivory in the dynamics and distribution of the tree cholla cactus (Opuntia imbricata), a long-lived perennial plant, across an elevational gradient in central New Mexico, USA, from low-elevation grassland $(1670 \mathrm{~m})$ to a grassland-mountain transition zone $(1720 \mathrm{~m})$ to the rocky slopes of the Los Pinos Mountains $(1790 \mathrm{~m})$. Tree cholla density increased significantly with elevation, while abundance of and damage by a suite of native, cactus-feeding insects decreased. We combined field experiments and demographic models to test the hypothesis that systematic spatial variation in chronic insect herbivory limits the tree cholla distribution to a subset of suitable habitat across the gradient. Our results support this hypothesis.

We found that key demographic functions (survival, growth, fecundity) and the responses of these functions to experimental reductions in insect herbivory varied across the gradient. The effects of insect exclusion on plant growth and seed production were strongest in the lowelevation grassland and decreased in magnitude with increasing elevation. We used the experimental data to parameterize integral projection models (IPM), which predict the asymptotic rate of population increase $(\lambda)$. The modeling results showed that insect herbivory depressed $\lambda$ and that the magnitude of this effect was context-dependent. The effect of insect herbivory on population growth was strongest at low elevation $\left(\Delta \lambda_{\text {low }}=0.095\right)$, intermediate at mid elevation $\left(\Delta \lambda_{\text {mid }}=0.046\right)$, and weakest at high elevation $\left(\Delta \lambda_{\text {high }}=-0.0089\right)$. The total effect of insects on $\lambda$ was due to a combination of reductions in growth and in fecundity and their combination; the relative contribution of each of these effects varied spatially. Our results, generated by experimental demography across a heterogeneous landscape, provide new insights into the role of native consumers in the population dynamics and distribution of abundance of long-lived native plants.
\end{abstract}

Key words: cactus-feeding insects; Cahela ponderosella; Chihuahuan Desert, New Mexico, USA; elevation gradient; herbivory; integral projection model; Opuntia imbricata; plant-insect interactions; population dynamics.

\section{INTRODUCTION}

Nearly every plant, at some point in its life cycle, is attacked by an animal. Given the ubiquity of plantconsumer interactions, predicting their outcomes and identifying conditions that mediate these outcomes are important conceptual challenges, as well as practical issues in the contexts of plant conservation (e.g., Bevill et al. 1999, Stiling et al. 2004, Louda et al. 2005) and biological control of weeds (e.g., McEvoy et al. 1993, Shea and Kelly 1998). The extent to which consumers influence the abundance, dynamics, and distribution of their host plant populations has been a topic of

Manuscript received 20 September 2007; revised 7 March 2008; accepted 23 April 2008. Corresponding Editor: W. P. Carson.

${ }^{3}$ Present address: Department of Biological Science, Florida State University, Tallahassee, Florida 32306-4295 USA. E-mail: tmiller@bio.fsu.edu persistent debate (Hairston et al. 1960, Ehrlich and Birch 1967, Harper 1977, Strong et al. 1984, Louda 1989a, Crawley 1990, Louda et al. 1990, Bigger and Marvier 1998, Strauss and Zangerl 2002, Halpern and Underwood 2006, Maron and Crone 2006). On the one hand, there is a vast literature, from both natural and managed systems, documenting the injurious effects of herbivory on the vegetative performance and reproductive success of individual plants (reviewed in Crawley 1989, 1997). On the other hand, understanding whether and how the individual-level consequences of herbivory translate to the population level is a far more complex line of inquiry, the importance of which has been recently highlighted (Halpern and Underwood 2006, Maron and Crone 2006).

The problem in linking individual plant performance to population dynamics is that individuals are but small pieces of a larger demographic puzzle. In structured 
populations, individuals that differ in size or stage make unequal contributions to overall population growth and dynamics (Caswell 2001). Therefore, quantifying the population-level effects of individual-level losses to consumers requires in-depth understanding of the manner in which the frequency and intensity of herbivory vary among individuals of different size or stage and the relative contributions of those sizes or stages to population dynamics. The development of quantitative tools, such as matrix population models (Caswell 2001) and, more recently, integral projection models (Easterling et al. 2000, Ellner and Rees 2006), has facilitated advances in our understanding of the demographic consequences of plant-herbivore interactions. There are now a number of observational and experimental studies based on these approaches that demonstrate negative effects of herbivory on $\lambda$, the asymptotic rate of population increase (Bastrenta et al. 1995, Ehrlen 1995, 2003, Shea and Kelly 1998, Parker 2000, Knight 2004, Louda et al. 2005, Rose et al. 2005, Kauffman and Maron 2006). Inferences regarding the outcomes of such interactions under natural conditions are somewhat limited, however, since many studies to date have focused on the effects of invasive herbivores or intentionally released biological control agents (which may experience relaxed predation pressure in a novel environment). Thus, although available data clearly indicate that herbivores can play an important role in the limitation and dynamics of plant populations, current challenges include developing a predictive framework for the demographic effects of native insects on native plants and identifying factors that mediate the magnitude of these effects (Maron and Crone 2006, Agrawal et al. 2007).

The frequency and intensity of plant-herbivore interactions often vary dramatically across habitats and along gradients of environmental conditions (e.g., Louda 1982a, 1983, 1989a, Denno and McClure 1983, Gange et al. 1989, Root and Cappuccino 1992, Parker 2000, Sipura et al. 2002, Bradley et al. 2003, Fagan et al. 2005, Gomez 2005, Maron and Kauffman 2006, Kolb et al. 2007). If spatial variation in herbivory is coupled with strong demographic effects on host plants, then herbivores could play an important role in the spatial distribution of plant population abundance. Indeed, experimental studies have demonstrated that systematic variation in herbivore pressure between contrasting environments or along gradients can alter relative plant abundances among otherwise suitable habitats (Louda 1982a, b, 1983, Louda et al. 1987, Louda and Rodman 1996, Fagan and Bishop 2000, Rand 2002, Fine et al. 2004, Gomez 2005), patterns that might be interpreted as abiotic constraints on distributional limits. Yet the general importance of differential herbivory, relative to abiotic factors, as a mechanism structuring the spatial distribution of plant populations remains unresolved (Louda 1989a, Maron and Crone 2006).
Plant life-history traits could also mediate the magnitude of herbivore effects (Crawley 1989, Louda and Potvin 1995, Kelly and Dyer 2002). Populations of short-lived perennial, fugitive species that rely on current seed rain for recruitment are hypothesized to be highly vulnerable to consumer effects, particularly by flower-, fruit-, and seed-feeding insects (Louda 1989b, Louda and Potvin 1995). In contrast, populations of long-lived, iteroparous perennial plants are thought to be buffered from demographic effects of herbivory due to their high adult survival and longevity (Maron and Gardner 2000, Maron and Crone 2006). Population growth by long-lived perennials is generally highly sensitive to established plant growth and persistence (Silvertown et al. 1993), suggesting that herbivory on these plants should have negative effects on population dynamics only if it reduces the survival and growth of large, mature individuals (but see Ehrlen 2003, Maron and Crone 2006). However, predictions regarding the influence of life-history variation on plant-herbivore interaction outcomes are difficult to evaluate because relatively few studies have examined the effects of consumers on the dynamics of long-lived perennial plants (Louda 1982a, b, Doak 1992, Bastrenta et al. 1995, Ehrlen 1995, Fagan and Bishop 2000, Kelly and Dyer 2002, Warner and Cushman 2002, Knight 2004, Kauffman and Maron 2006).

Herbivore feeding guild (e.g., seed predators vs. foliar herbivores) might also influence the consequences for plant population dynamics. Maron and Crone (2006) compared studies that quantified effects on $\lambda$ by flower- and seed-feeders with studies that quantified effects by vegetative herbivores and found equal to slightly stronger effects in populations that experienced reproductive vs. vegetative losses. Most plants, however, interact with both reproductive and vegetative herbivores simultaneously, suggesting the need to quantify the relative effects of reproductive losses, chronic vegetative damage, and their joint effects within populations subject to both types of damage (e.g., Ehrlen 1995, 2003).

We examined the role of herbivory by native insects in the population dynamics and landscape-scale distribution of a native, long-lived perennial plant. Our goal was to remedy current gaps in our understanding of the demographic consequences of plant-consumer interactions. Our research focused on the tree cholla cactus (Opuntia imbricata [Haworth] D.C.) and its interactions with insect herbivores in the Chihuahuan Desert, New Mexico, USA. Tree cholla is long-lived ( $>20$ years) and is attacked by a diverse assemblage of specialist insects, including floral feeders, predispersal seed predators, and insects that feed internally and externally on vegetative structures (Mann 1969, Moran 1980, Miller 2007b). Thus it provides an excellent model system in which to evaluate the effects of multiple consumer guilds on perennial plant demography. 
This paper focuses on variation in tree cholla-insect interactions across an elevational habitat gradient in central New Mexico, from the low-elevation grasslands of the Rio Grande valley to the rocky slopes of the Los Pinos Mountains. We used a combination of observational data, field experiments, and demographic modeling to address the following questions: (1) Do the frequency and intensity of interactions with cactusfeeding insects vary across the elevational gradient? (2) Do insect herbivores reduce the rate of cactus population growth $(\lambda)$ and, (3) if so, do these effects vary spatially? Answers to these questions led us to ask: (4) Does spatial variation in insect herbivory limit the distribution of tree cholla across the elevational gradient? To address the latter question, we tested the prediction that the effect of herbivory on tree cholla population growth $(\Delta \lambda)$ is greatest where the plants are most rare and weakest where the plants are most abundant. Finally, we asked: (5) What are the relative contributions of vegetative and reproductive losses toward the total demographic effect of herbivory, and do these contributions vary across the gradient?

\section{Methods}

\section{Natural history of focal species}

The tree cholla cactus (Opuntia imbricata) is an iteroparous perennial ( $>20$-year life span) that is common throughout the Chihuahuan Desert and arid grassland habitats of the southwest United States (Benson 1982). These plants grow in discrete, photosynthetic stem segments and lack persistent true leaves. Mature plants can reach $2 \mathrm{~m}$ in height and $1 \mathrm{~m}$ in crown width. At the start of each growing season (April), undifferentiated meristems appear at the ends of cactus branches, and meristems subsequently differentiate into either new stem segments or flower buds (Bowers 1996, Miller et al. 2006). Newly produced stem segments elongate from May through August. Flowering occurs in June, and fruits ripen and fall off plants in August. Tree cholla flowers are pollinated by bees and beetles (McFarland et al. 1989). Seedling germination is triggered by the late-summer monsoon rains and is typically followed by high seedling mortality (see Results). While many Opuntia cacti are capable of vegetative reproduction, tree cholla recruitment at our study sites occurs exclusively via seeds (Miller 2007c).

Throughout its range, tree cholla is attacked by a suite of insect herbivores that specialize on cacti in the genus Opuntia. There were four common cactus-feeding insects at our study sites. (1) The cactus bug (Narnia pallidicornis Stål [Hemiptera: Coreidae]), a haustellate sapfeeder, attacks all cactus parts but prefers developing flower buds and fruits (Mann 1969). Two partially overlapping bug generations occur during the tree cholla growing season (May-September), and adults overwinter among debris at the base of host plants. The dynamics of tree cholla-cactus bug interactions have been intensively studied (Miller et al. 2006, Miller 2007a,
2008), and damage by this herbivore is known to induce floral abortions (Miller et al. 2008). (2) The long-horned cactus beetle (Moneilema appressum LeConte [Coleoptera: Cerambycidae]), a mandibulate stem-borer, is active from June through August. Herbivory by adult beetles on stem segments and reproductive structures leaves distinctive damage marks. In late summer, adults lay eggs within bite marks and larvae burrow into the plant, overwinter internally, and emerge as adults the following year. (3) An unidentified weevil (Gerstaekeria sp. [Coleoptera: Curculionidae]) also feeds externally on both vegetative and reproductive structures as adults and overwinters as larvae within the plant. (4) Tree cholla seeds are attacked by a predispersal seed predator (Cahela ponderosella Barnes \& McDunnough [Lepidoptera: Pyralidae]). Adult moths oviposit into open cactus flowers, and larvae burrow into the ripening ovary. There is generally one larva per infested flower or fruit. The larval entrance hole leaves a distinctive scar, so fruit infestation can be scored unambiguously (Pickett and Clark 1979, Miller 2007b).

\section{Study sites}

This study was conducted at the Sevilleta National Wildlife Refuge (NWR), a Long Term Ecological Research (LTER) site in central New Mexico $\left(34^{\circ} 20^{\prime} 5.3^{\prime \prime} \mathrm{N}, 106^{\circ} 37^{\prime} 53.2^{\prime \prime} \mathrm{W}\right)$. The Sevilleta NWR occurs at a transition zone between Chihuahuan Desert and short-grass steppe. Annual precipitation averages $245 \mathrm{~mm}$ per year, and mean monthly temperatures range from $2.2^{\circ} \mathrm{C}$ in January to $23.1^{\circ} \mathrm{C}$ in July (Sevilleta LTER meteorological data, 1989-1999). Most precipitation falls during monsoon storms from July through September. The Sevilleta NWR has not been grazed since 1973. We conducted our work on the east side of the refuge, at three positions ("zones") along an elevational habitat gradient: low-elevation grassland (1670 $\mathrm{m})$, mid-elevation grassland/mountain transition zone (1720 m), and the high-elevation, rocky slopes of the Los Pinos Mountains $(1790 \mathrm{~m})$; see photo in Appendix A. Distance from the low to the high habitat is $\sim 2 \mathrm{~km}$. Soils ranged from fine to gravelly to rocky alluvium with increasing elevation (USDA 1989). While few long-term data exist on physical variation along the gradient, we know that daytime temperatures in July-August are $2-3^{\circ} \mathrm{C}$ hotter at high vs. low elevation (A. J. Rominger, unpublished data). Also, woody species (Dalea, Erigonium, Juniperus) increase in abundance at higher elevations, as do both plant species diversity and functional group diversity; however, total plant cover peaks at mid elevation (A. J. Rominger, unpublished data).

\section{Spatial variation in tree cholla density}

We quantified variation in established tree cholla density across the elevational habitat gradient in September 2004. We walked 100-m north-south transects within each zone ("perpendicular" to the gradient; 
$n=10$ per zone) and counted all plants that occurred within $1 \mathrm{~m}$ on either side of the transect. Transects were located haphazardly within each zone by blindly tossing a ball, and adjacent transects were separated by at least $100 \mathrm{~m}$. We tested for spatial variation in density (per 200 $\mathrm{m}^{2}$ ) using ANOVA on square root-transformed data.

\section{Insect exclusion experiment}

To quantify insect occurrence and herbivory on tree cholla and to determine whether herbivore effects varied along the habitat gradient, we excluded insects from cacti in each elevation zone for three consecutive growing seasons (2004-2006). To replicate zone effects, the experiment was conducted along three transects ("parallel" to the gradient) that crossed through each elevation zone (see photo in Appendix A); adjacent experimental transects were separated by at least $1 \mathrm{~km}$. We established three blocks along each transect, corresponding to the low, mid, and high zones; because the gradient was continuous, we separated adjacent blocks by $\sim 1 \mathrm{~km}$ to maximize variation among the three zones. In May 2004, we selected and flagged 70 tree cholla within each block. These were randomly selected among in situ plants, but stratified to represent the population size structure: 20 small juveniles $(<0.25 \mathrm{~m}$ height, pre-reproductive), 20 large juveniles $(>0.25 \mathrm{~m}$ height, pre-reproductive), and 30 adults $(>0.75 \mathrm{~m}$ height, reproductive). Within each block, 10 individuals of each size/stage class were randomly assigned to the insect exclusion treatment, and 10 were assigned to the water treatment ("water control"). Plants assigned to the insect exclusion treatment were sprayed with the nonsystemic insecticide carbaryl (1-naphthyl N-methlycarbamate), which was diluted to $266 \mathrm{~mL}$ active ingredient per $3.79 \mathrm{~L} \mathrm{H}_{2} \mathrm{O}$. Plants assigned to the water-only control were sprayed with an equal amount of water. The remaining 10 adult plants in each block were unmanipulated ("dry control"). This experiment included a total of 643 plants distributed across the gradient (one low-elevation block had 13 additional adult plants).

Insecticide and water treatments were applied every two weeks from mid-May to early September of 2004, 2005, and 2006. In a greenhouse experiment, we found that persistent applications of carbaryl had no direct effects on tree cholla growth (Appendix B; see also Lau and Strauss 2005). We did not apply treatments in the field on dates when the cacti had any open flowers (to avoid negative effects on pollinators, which include native and locally rare specialist bees), and so plants in all treatments remained vulnerable to Cahela, the seedfeeding moth that oviposits into cactus flowers. We included both the water control and dry control treatments for a subset of the experimental plants to evaluate whether the water applied with the insecticide had any unintended effects. We found no differences in insect damage or plant performance between water control and dry control treatments (Appendix C), so we pooled these two treatments and hereafter consider them as a single "control" treatment.

We measured the heights and widths of all plants in the experiment and recorded their survival in May of 2004, 2005, 2006, and 2007. We revisited the plants in July of each year (after the flowering period) and quantified the total number of developing fruits, including the number of fruits infested with a Cahela larva. We also recorded the number of insect damage marks (long-horned beetle bites, weevil bites, chlorotic marks left by sucking bugs, signs of internal feeding) on randomly selected new (i.e., produced that year) stem segments ( $n=6-10$ randomly selected segments per plant). In May, July, and September of each year, we quantified the abundances of the external-feeding cactus herbivores (bugs, beetles, and weevils). In September of each year, we collected 10 randomly selected fruits from each reproductive plant in the experiment (for plants with fewer than 10 fruits, all fruits were collected). Fruits were taken to the laboratory, dried for $36 \mathrm{~h}$ at $80^{\circ} \mathrm{C}$, and weighed. The relationship between fruit mass and number of seeds was used to estimate the number of seeds produced by each plant in each year (see Model parameterization).

We collected additional data on insect abundance and damage from the adult plants on one transect $(n=103)$ during a pilot study in 2003. We use these observational data to further evaluate the temporal consistency of patterns of herbivory across the gradient.

\section{Analysis of variation in herbivory across the gradient}

We used data from the insecticide experiment to quantify variation in insect abundance and damage across the gradient and to evaluate the efficacy of our insect exclusion treatment. Specifically, we analyzed three response variables, each measured at the per-plant level. First, herbivore load, a measure of herbivore abundance relative to plant resources, was calculated as the total mass (in grams) of all external-feeding insects (bugs, beetles, and weevils) observed across all sampling dates, divided by the number of flower buds and new stem segments (the primary resources for these insects). Further details on how herbivore load was estimated are given in Miller (2007b). Given the amount of time between censuses (more than one month), it is unlikely that we re-encountered individual insects from one census to the next. Second, we calculated the number of damage marks per stem segment; and third, we calculated the proportion of cactus fruits infested with Cahela larvae.

We analyzed variation in herbivore load and herbivore damage marks using repeated-measures ANOVA with zone, treatment, and year as fixed effects, transect as a random effect, an autoregressive error structure, and individual plants as the units of repeated observation. We pooled data across size/age classes for these analyses because these response variables are already standardized for variation in plant size. We analyzed 
fruit infestation by moths using a similar statistical model but, because our insecticide applications were not intended to reduce predispersal seed predation, this model did not include an effect of herbivore treatment. Analysis of fruit infestation was restricted to reproductive plants. Data were transformed (square root or arcsine square root) if necessary to meet test assumptions. Statistical models were implemented in SAS version 9.1 (SAS Institute, Cary, North Carolina, USA).

\section{Seed survival, seedling recruitment, and seedling survival}

Because our insecticide experiment focused on established plants, we conducted additional observations and experiments with early tree cholla stages not represented in the insecticide experiment to develop a more complete demographic picture and to estimate parameters for the demographic models.

We quantified the probability that a seed survives the transition from the maternal plant to the soil by tracking fruits. In August 2004, we selected 24 plants in each elevation zone (eight plants on each of the three transects), counted the number of ripening fruits on the plant, and cleared all fruits on the ground within a 2$\mathrm{m}$ radius. We revisited these plants on 14 February 2005 and counted the number of fruits remaining on the plant, the number of intact fruits on the ground within the $2-\mathrm{m}$ radius, and the number of empty fruits on the ground within the 2-m radius. Rodents and birds often chew out seeds once the fruits fall to the ground, leaving empty fruit shells as evidence (T. E. X. Miller, personal observation). We used fruits as proxies for seeds and estimated seed survival per plant as the number of undamaged fruits on the ground divided by the number of fruits produced by the plant in the previous growing season. Because our census interval included only half of the period in which seed mortality can occur, we divided our estimates of seed survival by half to represent seed losses over a full year (which assumes constant levels of predation pressure).

To evaluate the importance of seed availability (vs. microsite limitation) for recruitment, we conducted a seed addition experiment. We established 12 seed addition blocks in each elevation zone (low, mid, high). Within each block there were nine $0.25 \times 0.25 \mathrm{~m}$ plots. Plots within blocks were randomly assigned to one of three seed addition treatments: 0 (control), 100, or 250 seeds. We chose these levels to represent the range of seeds within an individual cactus fruit (i.e., the experiment roughly mimics "rain" of a single fruit into a plot). To replicate zone effects, blocks were evenly distributed across four transects (three blocks per transect per zone); three of these were the same transects used for the insecticide experiment. Blocks were located haphazardly within each zone by tossing a ball, but locations were sometimes adjusted to avoid obstacles (like boulders or large cacti). We predicted that seedling recruitment would be greatest in the high-elevation zone, where ambient cactus density was greatest (see Results), based on the assumption that plant density is an indicator of habitat suitability.

Seeds were added to plots on 10-12 January 2004 by scattering and lightly poking them beneath the soil surface. At the time of seed addition, we categorized vegetation cover (grasses and forbs) in each plot into one of four categories corresponding to $25 \%$ cover intervals, which allowed us to roughly evaluate any effects of interspecific interactions on germination and seedling survival. We quantified seedling recruitment on 9-10 August 2004, after the onset of the summer monsoon season. We compared recruitment among elevation zones and seed addition treatments using ANOVA with transect and block within transect as random effects. We interpreted the difference in recruitment between 100- and 250-seed addition treatments as the degree of seed limitation, and we used preplanned contrasts to determine whether the degree of seed limitation varied across the gradient. Again, we predicted that seed limitation would be greatest at high elevation, where ambient cactus density was also greatest (see Results).

We revisited the seed addition plots on 30-31 August 2005 and again on 13-14 August 2006 and quantified survival by counting remaining plants. We also measured size (height and width) of seedlings and surviving plants. We did not apply insecticide treatments to these plants because we did not observe insects or evidence of insect feeding on the smallest plant sizes. Plants of this size are, however, susceptible to vertebrate (rodent and rabbit) herbivores; the demographic consequences of these interactions are beyond the scope of the present study.

\section{Integral projection model}

We used an integral projection model (IPM: Easterling et al. 2000, Rose et al. 2005, Ellner and Rees 2006) to evaluate whether and how the effects of insect herbivory on individuals translate to cactus population dynamics. The IPM is an integro-difference equation that predicts population growth in discrete time by integrating demographic contributions across all plant sizes. These models consist of continuous functions that describe size-dependent survival, growth, and fecundity. In contrast to matrix population models, IPMs do not require that individuals be binned into discrete size or stage classes, decisions that are often arbitrary and that can influence model output (Ramula and Lehtila 2005). In addition, the use of continuous functions means that IPMs generally require far fewer estimated parameters than matrix models. However, like matrix models, there is well-developed theory for estimating from IPMs the asymptotic rate of population growth $(\lambda)$ and sensitivities and elasticities of $\lambda$ to changes in demographic rates (Easterling et al. 2000, Ellner and Rees 2006).

The tree cholla IPM describes change in population size $(n)$ over annual time steps $(\Delta t=1 \mathrm{yr})$. The full model takes the following form: 


$$
n(y, t+1)=\int_{\Omega}[p(x, y)+f(x, y)] n(x, t) d x .
$$

The survival-growth component, $p(x, y)$, can be broken down such that

$$
p(x, y)=s(x) g(x, y)
$$

where $s(x)$ is the probability that an $x$-sized individual survives from one growing season to the next and $g(x, y)$ describes the growth of a plant from size $x$ to size $y$ over the same time interval.

The reproduction component, $f(x, y)$, represents the production of $y$-sized individuals from $x$-sized maternal plants such that

$$
f(x, y)=s(x) f_{n}(x) p_{\mathrm{E}} f_{\mathrm{d}}(y)
$$

where $s(x)$ is size-specific survival, $f_{n}(x)$ is the number of seeds produced by an $x$-sized plant, $p_{\mathrm{E}}$ is the probability that a seed becomes a seedling, and $f_{\mathrm{d}}(y)$ is the size distribution of seedlings. Together, $p(x, y)$ and $f(x, y)$ form the IPM "kernel," a surface that describes the frequency of all demographic possibilities over a single time step (the IPM kernel is analogous to the population projection matrix). Since this kernel dictates the population dynamics, our task was to determine whether and how environmental context, herbivory, and their interaction influence its shape.

\section{Model parameterization}

We parameterized the tree cholla IPM using demographic data from our field experiments and observations. The temporal coverage of our demographic data (three interannual transitions) was insufficient to build a stochastic population model, and so we pooled data across all years of the study (three interannual transitions) to represent a single $t$ to $t+1$ time step (see also Easterling et al. 2000, Rose et al. 2005, Ellner and Rees 2006, Kolb et al. 2007). For readers interested in the temporal variation, we partition our analysis by year in Appendix G. The size variable for our model was plant volume (in cubic centimeters), estimated as the volume of an inverted cone based on measurements of height and crown width. We fit all IPM functions to the natural logarithm of plant volume. Model construction and analysis were conducted in $\mathrm{R}$ ( $\mathrm{R}$ Development Core Team 2008).

We used Akaike Information Criterion (AIC)-based model selection methods (Burnham and Anderson 2002) to determine whether the shapes of the survival, growth, and fecundity functions differed among elevation zones, among herbivory treatments, or both. First, for survival, $s(x)$, we fit a logistic regression model to binomial data (survived/died). We did not test for differences in survival between herbivory treatments because only five plants died from 2004 to 2007 out of the 643 plants in the insecticide experiment $(<1 \%)$, so we had little power to detect an effect of herbivory on survival of established plants. There was, however, substantial mortality among the recruits in our seed addition plots, allowing us to test for effects of elevation zone on survival. We compared the fit of a model with zone-specific parameters to that of a "null" model in which the slope and intercept parameters were constant across all zones.

Next, for the growth function, $g(x, y)$, we compared the fit of a null growth model with constant parameters to models with zone-, treatment-, or zone $\times$ treatmentspecific parameters. A preliminary analysis indicated that a polynomial function described tree cholla growth better than a linear one $(\triangle \mathrm{AIC}=234.9)$. Because we did not apply insecticide treatments to seedlings and early cactus stages and because the sample sizes for growth estimates of these plants were small (due to high seedling mortality), we included all of the data from the seed addition plots in all of the candidate growth models, regardless of zone or treatment effects. Thus, we assumed that the very early growth trajectory was universal and investigated the effects of elevation zone and herbivory on the remainder of the growth curve.

For the fecundity function, $f_{n}(x)$, we used a negative binomial model to describe size-specific seed production and, as above, compared the fit of a null model with constant parameters to models with zone-, treatment-, or zone $\times$ treatment-specific parameters. For each plant in each year, we estimated seed production by multiplying counts of ripening fruits in July by the mean number of seeds per fruit. The number of seeds per fruit was estimated for each plant from the fruit mass data using to the relationship: seeds $=-48.94+73.12$ (fruit mass) $\left(F_{1,92}=235.05, P<0.0001, R^{2}=0.72\right)$. Fruits attacked by the moth Cahela contained $55 \%$ fewer viable seeds than did uninfested fruits (Miller 2007b). Therefore, estimates of seed production by control plants accounted for the effects of moth infestation (based on counts of infested and uninfested fruits on each plant), while seed production for insecticide plants was calculated as though all fruits were uninfested. Thus, while we did not exclude predispersal seed predators from plants in the field, we applied a correction factor (55\% increase in the seed content of infested fruits) to eliminate their effects in the data analysis. We conducted a sensitivity analysis to evaluate the consequences of uncertainty in this estimate of Cahela damage. As above, we included all seedling and one-year-old data in all candidate fecundity models, regardless of zone or treatment. In all model contests, we used $\mathrm{AIC}_{\mathrm{c}}$ (sample size-corrected AIC) and Akaike weights ( $\left.w_{i}\right)$ to quantify the proportion of evidence (provided by the data) in favor of each candidate model (Burnham and Anderson 2002).

We found a gap in our demographic data set corresponding to plants larger than the largest recruit in our seed addition plots but smaller than the smallest established plant we found to include in the insecticide experiment (-1.6 to $2.1 \ln \left[\mathrm{cm}^{3}\right]$; see Figs. 4 and 5). Thus, we assume that the functions we fit to the data available provide a reasonable approximation for plants within that size interval. 
Finally, we estimated the probability of establishment $\left(p_{\mathrm{E}}\right)$ for each elevation zone by multiplying the mean seed survival rate by the mean germination rate observed in the seed addition experiment (seedlings counted per seed added). In our ongoing studies, we have observed no relationship between current seed rain and seedling recruitment in our seed addition plots, so we set $p_{\mathrm{E}}$ to a density-independent constant (see also Rose et al. 2005, Ellner and Rees 2006). We conducted a sensitivity analysis to evaluate the consequences of uncertainty in our estimates of $p_{\mathrm{E}}$. The distribution of seedling size was determined from the mean and variance of seedlings measured in our seed addition plots ( $\ln [$ seedling size] $\sim N[-4.15,0.38])$.

This parameterization process yielded IPM kernels that were specific to each herbivory $\times$ zone combination. We discretized each kernel into matrices $(200 \times 200)$ and calculated the asymptotic population growth rate, $\lambda_{i j}$, as the dominant eigenvalue of each corresponding matrix (where $i$ and $j$ represent zone [low, mid, high] and herbivory [+, -] effects, respectively). The upper integration limit of the model was adjusted for each zone to reflect the maximum plant size at which we had data for both the control and insecticide treatments. The lower integration limit, corresponding to the smallest seedling we observed, was constant across zones. We also calculated elasticity surfaces (Easterling et al. 2000) of the control kernels for each zone to evaluate, under ambient conditions, how proportional changes in demographic rates influenced $\lambda$. Since our question focused on how the differences in $\lambda$ with vs. without herbivory varied in magnitude across the gradient (see following section), we did not test for treatments effects per se.

\section{Demographic consequences of herbivory and its effect on growth vs. fecundity}

For each elevation zone (we drop zone subscripts here to minimize notation), we calculated the total demographic effect of insect herbivory as the difference in $\lambda$ between the insecticide and control treatments $\left(\Delta \lambda=\lambda_{-}\right.$ $\left.-\lambda_{+}\right)$. We also partitioned this difference between effects on plant growth vs. effects on fecundity by calculating

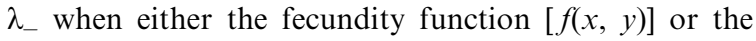
growth function $[g(x, y)]$ in the insecticide kernel was replaced with the corresponding function from the control treatment. This generated expected population growth rates if the effects of herbivory were restricted either to plant growth $\left(\lambda_{\mathrm{G}}\right)$ or to plant fecundity $\left(\lambda_{\mathrm{F}}\right)$. The differences between each of these values and the control value with ambient herbivory $\left(\lambda_{+}\right)$represent the independent demographic effects of herbivory that reduces growth $\left(\Delta \lambda_{\mathrm{G}}\right)$ and herbivory that reduces fecundity $\left(\Delta \lambda_{\mathrm{F}}\right)$. Any remainder in the total demographic effect once these independent effects are accounted for represents the joint, synergistic effect $\left(\Delta \lambda_{\mathrm{X}}\right)$ of insects simultaneously reducing plant growth and fecundity. These relationships can be summarized as follows:

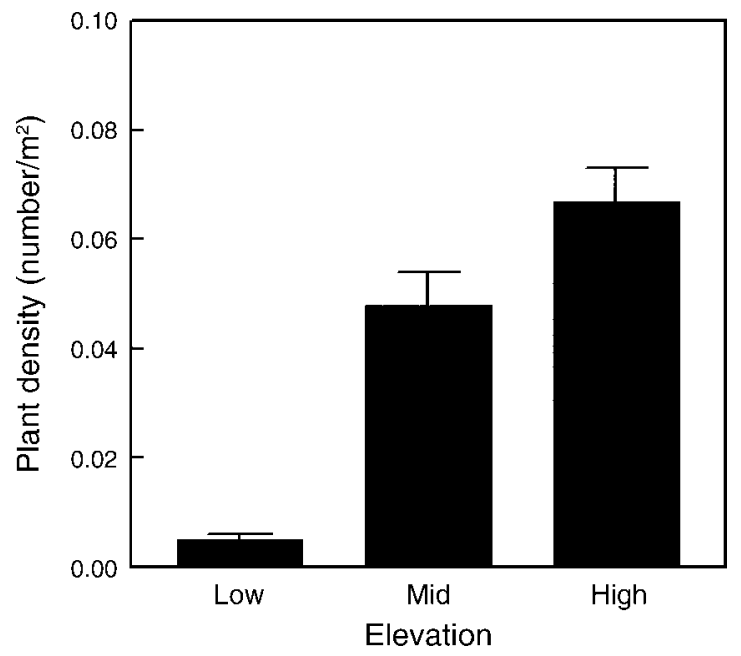

FIG. 1. Variation in tree cholla (Opuntia imbricata) density $($ mean + SE) across the desert grassland-Los Pinos Mountains elevational gradient. This study was conducted at the Sevilleta National Wildlife Refuge, New Mexico, USA.

$$
\begin{aligned}
\Delta \lambda & =\lambda_{-}-\lambda_{+} \\
\Delta \lambda_{\mathrm{G}} & =\lambda_{\mathrm{G}}-\lambda_{+} \\
\Delta \lambda_{\mathrm{F}} & =\lambda_{\mathrm{F}}-\lambda_{+} \\
\Delta \lambda_{\mathrm{X}} & =\Delta \lambda-\left(\Delta \lambda_{\mathrm{G}}+\Delta \lambda_{\mathrm{F}}\right) .
\end{aligned}
$$

Results

\section{Spatial variation in plant density and herbivory}

Densities of established tree cholla cacti varied across the grassland-mountain habitat gradient (Fig. 1). Plants were sparse in the low-elevation zone and increased in density with increasing elevation $\left(F_{2,27}=54.5, P<\right.$ $0.001)$. The frequency and intensity of interactions with insect herbivores and seed predators also varied across the gradient, and this variation was inversely correlated with established plant density. Generally, over the four years of the study, insect herbivore load (mass of insects per plant resource), herbivore damage marks, and the proportion of fruits infested on tree cholla were greatest at low elevation, where plant density was lowest, and declined with increasing elevation. Insecticide treatment significantly reduced herbivore load and herbivore damage, though the magnitude of this effect varied across years and zones (Fig. 2, Table 1). Notably, control and insecticide-treated plants at high elevation had similar amounts of damage in 2005 and 2006 (Fig. 2); the reasons for this are unclear, though it is possible that rodent damage there was mistakenly identified as insect damage.

\section{Spatial variation in seed survival and seedling recruitment}

Post-maturation seed survival from the maternal plant to the soil varied across the elevational gradient. Seeds at high elevation had lower survival probabilities 

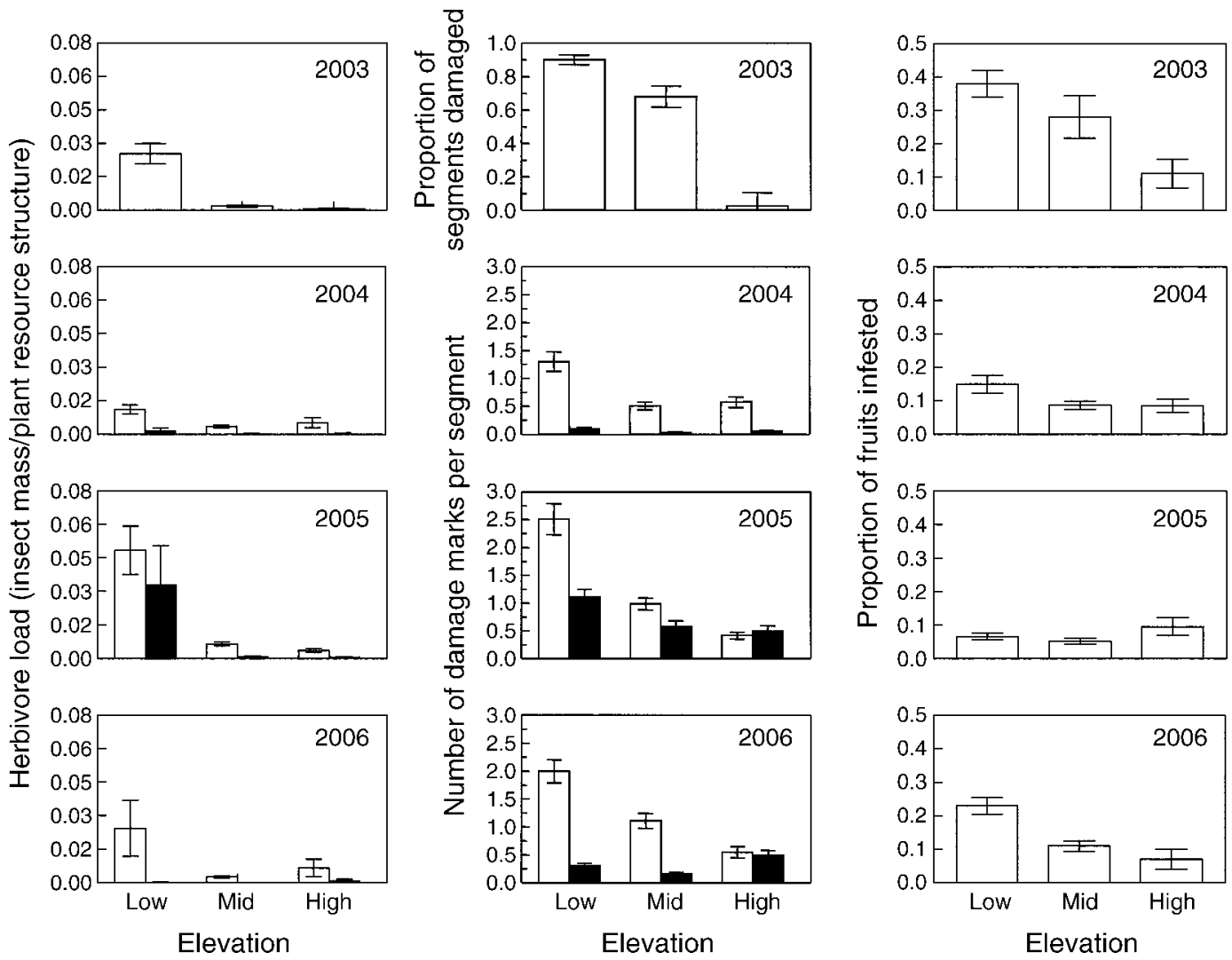

FIG. 2. Variation in herbivore abundance and damage (mean $\pm \mathrm{SE}$ ) in tree cholla across the elevational gradient (low-, mid-, and high-elevation zones) over four years (2003-2006). Herbivore load was calculated as the mass of insects per plant resource structure (stem segment or flower bud; see Methods: Analysis of variation in herbivory across the gradient). Herbivore damage was quantified in 2003 as the proportion of new segments with any sign of herbivore damage and in all subsequent years as the number of insect feeding damage marks per stem segment. The proportion of tree cholla fruits infested with a Cahela ponderosella larva is shown for 2003-2006. White and black bars represent control and insecticide treatments, respectively. Insecticide was not applied in 2003 (pilot year), and it was not used to reduce Cahela floral infestation in any year. See Table 1 for ANOVA results.

than seeds at low or mid elevation (Table $2 ; F_{2,60}=15.8$, $P<0.001$; post hoc comparisons with Tukey-adjusted $\alpha$ : low $=$ mid $>$ high). Observations suggest that these differences reflect variation in the intensity of fruit consumption by birds and rodents across the gradient (T. E. X. Miller, unpublished data).

Seedling recruitment in our seed addition plots also varied along the gradient. Contrary to our expectations based on the pattern of ambient plant density (Fig. 1), overall recruitment was greatest in the low-elevation habitat, where established plants were sparse, and recruitment declined at higher elevations, where established plants were more abundant (Fig. 3). We never observed tree cholla seedlings in plots in which we did not add seeds. In each elevation zone, increasing seed input led to greater numbers of seedlings, indicating that suitable microsites were not saturated at our levels of seed addition and that seed was limiting. The magnitude of seed limitation varied across the gradient, as indicated by a significant interaction of elevation zone and seed addition $\left(F_{4,322}=2.97, P=0.02\right)$. This interaction was driven by the greater difference between 100- and 250- addition plots (i.e., stronger seed limitation) at low elevation (preplanned contrast: $P=0.01)$ compared to mid $(P=0.46)$ or high elevation $(P=0.18)$. Germination rate in this experiment was quite low (seedling counts represent $<2 \%$ of seeds added). Tree cholla seeds are small and disc-shaped (1-2 mm diameter), but it is unlikely that seeds washed away after planting since we have observed continued recruitment in these plots from the 2004 pulse treatment (see Discussion). Per-plot germination rates were not related to percent cover of grasses and forbs in any elevation zone (test of variation among cover categories: $\left.F_{3,94}=0.94, P<0.42\right)$. The probability of establishment $\left(p_{\mathrm{E}}=\right.$ seed survival $\times$ germination) was greatest at low elevation and lowest at high elevation (Table 2).

\section{Effects of elevation zone and insect herbivory on demographic functions}

First, we found that the relationship between plant size and survival, $s(x)$, differed across the gradient. The field data more strongly supported a survival model with zone-specific parameters than they did a null model in 
TABLE 1. ANOVA results for three measures of insect herbivory (load, damage, and infestation) in response to variation in elevation zone (low, mid, high), herbivory treatment (insecticide, control), and year $(2004,2005,2006)$ in the tree cholla (Opuntia imbricata).

\begin{tabular}{lcrc}
\hline \hline \multicolumn{1}{c}{ Effect } & df & \multicolumn{1}{c}{$F$} & $P$ \\
\hline Herbivore load & & & \\
Zone & 2,1800 & 35.15 & $<0.0001$ \\
Year & 2,1800 & 116.62 & $<0.0001$ \\
Treatment & 1,1800 & 9.95 & $<0.0001$ \\
Zone $\times$ year & 4,1800 & 19.07 & $<0.0001$ \\
Zone $\times$ treatment & 2,1800 & 8.09 & $<0.0001$ \\
Year $\times$ treatment & 2,1800 & 0.73 & 0.48 \\
Zone $\times$ year $\times$ treatment & 4,1800 & 0.59 & 0.67 \\
Damage marks per segment & & & \\
Zone & 2,1804 & 65.81 & $<0.0001$ \\
Year & 2,1804 & 216.37 & $<0.0001$ \\
Treatment & 1,1804 & 27.02 & $<0.0001$ \\
Zone $\times$ year & 4,1804 & 59.61 & $<0.0001$ \\
Zone $\times$ treatment & 2,1804 & 7.99 & $<0.0001$ \\
Year $\times$ treatment & 2,1804 & 10.07 & $<0.0001$ \\
Zone $\times$ year $\times$ treatment & 4,1804 & 3.46 & 0.008 \\
Fruit infestation & & & \\
Zone & 2,723 & 20.58 & $<0.0001$ \\
Year & 2,723 & 11.79 & $<0.0001$ \\
Zone $\times$ year & 4,723 & 2.8 & 0.025 \\
\hline
\end{tabular}

Notes: Herbivore load was calculated as the mass of insects per plant resource structure (stem segment or flower bud; see Methods: Analysis of variation in herbivory across the gradient). Application of insecticide was not intended to reduce fruit infestation, so we did not test for a treatment effect on this response variable. This study was conducted at the Sevilleta National Wildlife Refuge, New Mexico, USA.

which the parameters were constant across the gradient (Table 3). The survival data and fitted functions are shown in Fig. 4. To further examine zone-related differences in survival, we calculated the plant size corresponding to a 0.5 survival probability $\left(x_{0.5}\right)$. Seedlings and small plants at mid elevation had a survival advantage over similarly sized plants at low elevation; survival of small plants was lowest at high elevation (low, $x_{0.5}=0.17 \mathrm{~cm}^{3}$; mid, $x_{0.5}=0.07 \mathrm{~cm}^{3}$; high, $x_{0.5}=0.38 \mathrm{~cm}^{3}$ ). Survival of established plants in the insecticide experiment was consistently high in both treatments at all elevation zones (Fig. 4), so we did not test for effects of insect herbivory on established plant survival. Like germination, seedling survival was not affected by grass/forb cover in the seed addition plots in any elevation zone $\left(F_{3,94}=1.04, P<0.37\right)$.

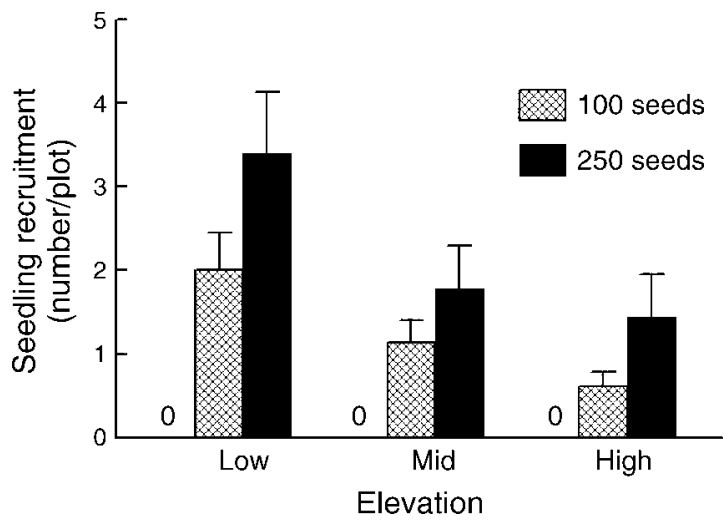

FIG. 3. Seedling recruitment (mean $+\mathrm{SE}$ ) in tree cholla across elevation zones in response to experimental additions of 0,100 , or 250 seeds to $0.25-\mathrm{m}^{2}$ plots. Where no seeds were added, there was no recruitment (zeros in figure).

Second, the growth function, $g(x, y)$, also varied across the gradient and was differentially affected by insect exclusion in each elevation zone. The growth data are shown in Fig. 5a-c and the fitted functions are shown in Fig. 5d-f. A polynomial growth model with zone- and treatment-specific parameters provided the best fit to the data (Table 3 ), reflecting habitat-specific differences in the plant growth response to herbivore exclusion. To highlight differences between insecticide and control growth functions and to visualize how treatment effects varied along the gradient, we also examined the difference between the two curves (insecticide - control) for each zone (Fig. $5 \mathrm{~g}-\mathrm{i}$ ). The humped shapes of the growth differences indicate that insect exclusion had the greatest positive effects on the growth of medium-sized plants. This effect was greatest at low elevation and weakest at high elevation (Fig. $5 \mathrm{~g}-\mathrm{i}$ ). The large reductions in size we estimated for some plants (see points below the 1:1 line in Fig. 5a-c) were verified by our time series of digital images of each plant in the experiment. Internal damage by beetle and weevil larvae sometimes caused entire sections of the plant to die off, causing severe reductions in plant size.

Third, we found strong variation in the fecundity function, $f_{n}(x)$, in response to both elevation zone and insect herbivory (Table 3). In Fig. 6, we show the seed production data $(\mathrm{a}-\mathrm{c})$, the fitted functions $(\mathrm{d}-\mathrm{f})$, and the difference between the insecticide and control curves

TABLE 2. Estimates (mean $\pm \mathrm{SE}$ ) for the probabilities of tree cholla seed survival and germination across the elevational habitat gradient.

\begin{tabular}{lccc}
\hline \hline Seed fate & Low & Mid & High \\
\hline Seed survival & $0.089 \pm 0.027$ & $0.139 \pm 0.025$ & $0.01 \pm 0.004$ \\
Germination & $0.017 \pm 0.0026$ & $0.0092 \pm 0.0016$ & $0.0059 \pm 0.0013$ \\
\hline
\end{tabular}

Note: The probabilities of establishment $\left(p_{\mathrm{E}}\right)$ used in the integral projection model are the product of mean seed survival and mean germination (low elevation, $p_{\mathrm{E}}=0.0015$; mid elevation, $p_{\mathrm{E}}=0.0013$; high elevation, $\left.p_{\mathrm{E}}=0.00006\right)$. 
a) Low elevation

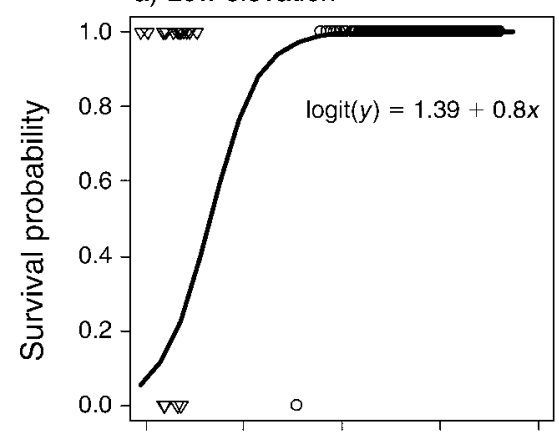

b) Mid elevation

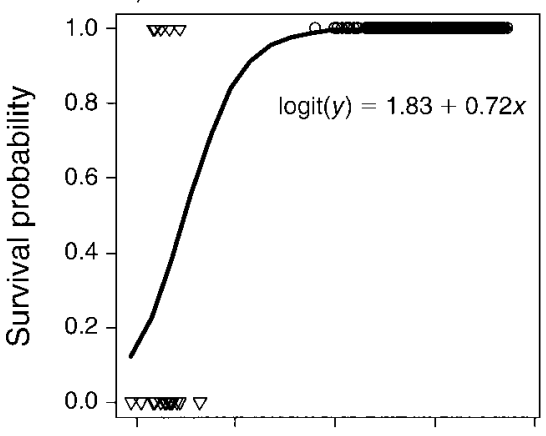

c) High elevation

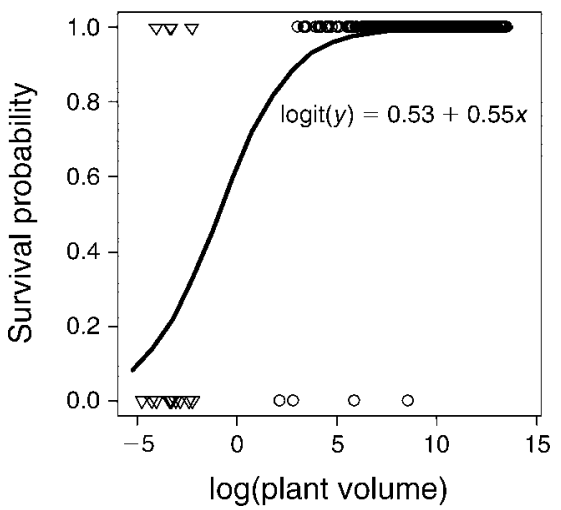

FIG. 4. Size-dependent survival of tree cholla in each elevation zone. Points at 0 and 1 on the $y$-axes represent plants that died and survived, respectively, over a one-year time step, and solid lines are the fitted functions for the (a) low-, (b) mid-, and (c) high-elevation zones. Triangles represent seedling and one-year-old plants that we monitored in the seed addition plots, and circles represent established plants included in the insecticide experiment. Due to high survival of established plants, we did not test for an effect of herbivory on survival.

(g-i). Seed production was strongly size-dependent in all zones, with the largest plants producing the most seeds. Maximum seed production was greatest at mid elevation, followed by low elevation, then high elevation, where seed production was substantially lower (Fig. 6ac). This zone-related variation was driven largely by differences in fruit mass (low, $2.94 \pm 0.065 \mathrm{~g}$; mid, 3.39 $\pm 0.18 \mathrm{~g}$; high, $2.18 \pm 0.094 \mathrm{~g}$ [mean $\pm \mathrm{SE}] ; F_{2,753}=$ 15.53, $P<0.0001)$. The effect of insect exclusion on tree cholla fecundity (insecticide curve - control curve) was greatest at low elevation, weaker at mid elevation, and weakest at high elevation (Fig. 6g-i). The reductions in seed production at low and mid elevation were likely driven by cactus bugs (Narnia pallidicnoris), whose damage induces flower bud abortion (Miller et al. 2008), and less so by the predispersal seed predator Cahela ponderosella (since the fecundity functions were only weakly sensitive to Cahela damage; Appendix F). At high elevation, by chance, predicted seed production was slightly greater for control plants than insecticide plants within a brief intermediate size interval (10-12.5 $\left.\ln \left[\mathrm{cm}^{3}\right]\right)$. This is difficult to see in Fig. 6 because axes were kept constant across zones, so we provide a rescaled view of the high-elevation data in Appendix D.

\section{Herbivore effects on plant dynamics and distribution}

The experimentally derived demographic functions and parameters were used to construct IPM kernels with and without insect herbivory for each elevation zone. Asymptotic rates of population growth $(\lambda)$, estimated from control IPM kernels, are given in Table 4. Population growth in the presence of insect herbivores $\left(\lambda_{+}\right)$was positive $(>1)$ at low and mid elevation and negative $(<1)$ at high elevation. However, all $\lambda_{+}$ estimates were close to one (range, 0.985-1.136), corresponding to roughly stable populations. Elasticity surfaces, representing the effects of proportional changes in the IPM kernel on $\lambda$, varied somewhat across elevation zones (these were calculated from control kernels only [ambient conditions]), as shown in Appendix E. This analysis indicates that stasis and growth of large, reproductive individuals were the most important demographic transitions, consistent with demographic trends in perennial plants (Silvertown et al. 1993) including other cacti (Godinez-Alvarez et al. 2003).

The effect of herbivory on $\lambda$ varied across the gradient. The difference in $\lambda$ between control conditions and insect exclusion $(\Delta \lambda)$ was greatest at low elevation, weaker at mid elevation, and weakest at high elevation (Fig. 7). We conducted a sensitivity analysis to determine whether uncertainty in the parameters for which we used rather coarse empirical estimates could influence this result. We found that the inverse relationship between ambient plant density and the demographic effects of insect herbivory $(\Delta \lambda)$ was robust to variation in our estimates for both $p_{\mathrm{E}}$ and the percentage of seeds per fruit destroyed by moth infestation (Appendix F). Also, while we pooled demographic data across years, the decline in $\Delta \lambda$ from low- to high-elevation zones was consistent when we partitioned the analysis by year (Appendix G).

For each zone, we partitioned the reduction in $\lambda$ due to insect herbivory among effects on growth $\left(\Delta \lambda_{\mathrm{G}}\right)$ vs. on fecundity $\left(\Delta \lambda_{\mathrm{F}}\right)$. At low elevation, the difference in $\lambda$ between control and insecticide treatments was driven by the effects of insects on both growth and seed production. Interestingly, the direct effects on growth 

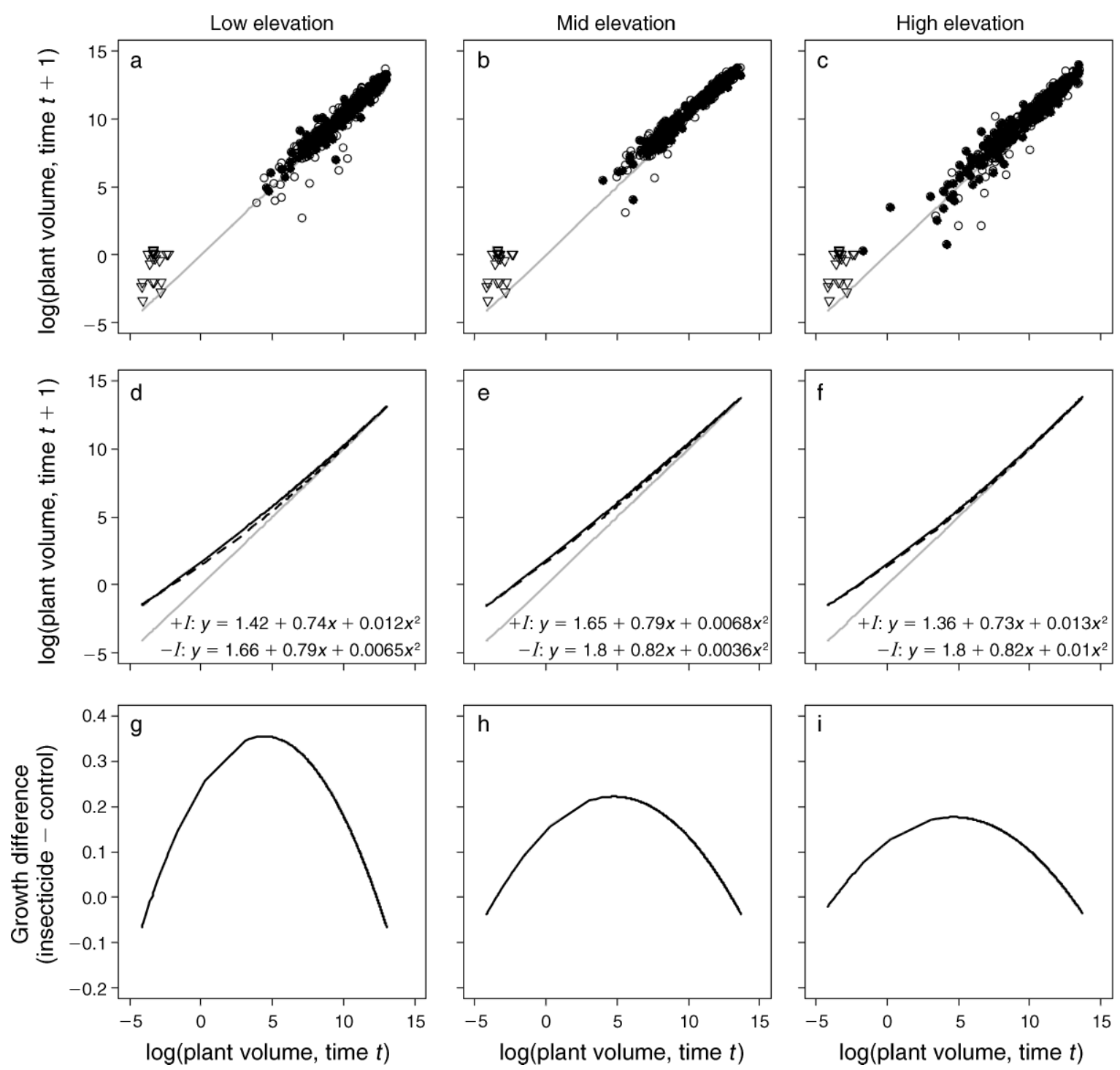

FIG. 5. Tree cholla growth in relation to elevation zone and insect herbivory. (a-c) Experimental data and (d-f) fitted functions for the relationship between future size ( $t+1, y$-axes) and current size $(t, x$-axes) for the low-, mid-, and high-elevation zones (open circles and dotted lines represent control; solid circles and solid lines represent insecticide treatment). Equations of fitted functions are given for each elevation zone under ambient $(+\mathrm{I})$ and reduced $(-\mathrm{I})$ insect herbivory. Thin gray lines show the 1:1 relationship (stasis). Triangles represent seedling and one-year-old plants that we monitored in our seed addition plots (not included in the insecticide experiment). Panels (g)-(i) show the difference between the fitted insecticide and control growth functions.

and fecundity, alone, did not account for the total demographic effect of insect herbivory. Rather, the joint, synergistic effect of reductions in both plant growth and fecundity also explained a fraction of the total response. At mid elevation, partitioning the total effect of herbivory yielded different relative contributions of the demographic functions. Here, the chronic low-level reduction in plant fecundity caused by insect herbivory was the dominant factor, whereas effects on growth contributed weakly to the total effect, and the interaction of growth and fecundity effects accounted for a small remainder (Fig. 7). At high elevation, the slightly negative $\Delta \lambda$ reflects the fact the fitted curve for seed production by control plants fell slightly above the insecticide curve (Fig. 6f, Appendix D), and this difference outweighed the positive effect of insect exclusion on growth (Fig. 5i).

Overall, results from the integral projection models indicate that the effects of insect herbivory on tree cholla population growth were inversely related to ambient tree cholla density along the grassland-mountain gradient (Figs. 1 and 7).

\section{Discussion}

Identifying the factors that structure the temporal and spatial dynamics of plant populations is broadly 
TABLE 3. Candidate models of tree cholla demographic functions (survival, growth, and fecundity) and results of model fitting.

\begin{tabular}{|c|c|c|}
\hline Model & $\mathrm{AIC}_{\mathrm{c}}$ & $w_{\mathrm{i}}$ \\
\hline \multicolumn{3}{|l|}{ Survival } \\
\hline $\begin{array}{l}\text { logit(survival) }=a+b \times \text { size }_{t} \\
\text { logit(survival) }=\boldsymbol{a}_{\boldsymbol{i}}+\boldsymbol{b}_{\boldsymbol{i}} \times \text { size }_{\boldsymbol{t}}\end{array}$ & $\begin{array}{l}455.77 \\
\mathbf{4 5 1 . 6 5}\end{array}$ & $\begin{array}{l}0.11 \\
\mathbf{0 . 8 9}\end{array}$ \\
\hline \multicolumn{3}{|l|}{ Growth } \\
\hline $\begin{array}{l}\text { Size }_{t+1}=a+b \times \text { size }_{t}+c \times \text { size }_{t}^{2} \\
\text { Size }_{t+1}=a_{i}+b_{i} \times \operatorname{size}_{t}+c_{i} \times \text { size }_{t}^{2} \\
\text { Size }_{t+1}=a_{j}+b_{j} \times \text { size }_{t}+c_{j} \times \text { size }_{t}^{2} \\
\text { Size }_{\boldsymbol{t}+\mathbf{1}}=\boldsymbol{a}_{\boldsymbol{i} \boldsymbol{j}}+\boldsymbol{b}_{\boldsymbol{i} \boldsymbol{j}} \times \mathbf{s i z e}_{\boldsymbol{t}}+\boldsymbol{c}_{\boldsymbol{i} \boldsymbol{j}} \times \text { size }_{\boldsymbol{t}}^{2}\end{array}$ & $\begin{array}{l}3316.2 \\
3256 \\
3296.6 \\
\mathbf{3 2 4 6 . 6}\end{array}$ & $\begin{aligned} 7.63 & \times 10^{-16} \\
& 0.01 \\
1.38 & \times 10^{-11} \\
& \mathbf{0 . 9 8}\end{aligned}$ \\
\hline \multicolumn{3}{|l|}{ Fecundity } \\
\hline $\begin{array}{l}\text { Seeds }=\exp \left(a+b \times \text { size }_{t}\right) \\
\text { Seeds }=\exp \left(a_{i}+b_{i} \times \text { size }_{t}\right) \\
\text { Seeds }=\exp \left(a_{j}+b_{j} \times \text { size }_{t}\right) \\
\text { Seeds }=\exp \left(\boldsymbol{a}_{i j}+\boldsymbol{b}_{i j} \times \text { size }_{t}\right)\end{array}$ & $\begin{array}{l}3180782 \\
2639081 \\
3162144 \\
\mathbf{2 6 0 2 2 3 9}\end{array}$ & $\begin{array}{c}<0.01 \\
<0.01 \\
<0.01 \\
\quad \mathbf{0 . 9 9 9}\end{array}$ \\
\hline
\end{tabular}

important, both conceptually and practically. Understanding the role of consumers in plant dynamics has been particularly challenging, due, in part, to the difficulty in inferring population-level effects from estimates of damage to individuals. Here we combined field experiments and demographic models to quantify the effects of chronic insect herbivory on plant population dynamics and distribution across a heterogeneous landscape. We proceed by addressing the questions with which we began, then interpreting our results in light of current theory regarding factors that mediate the effects of consumers on plant populations.

\section{Spatial variation in herbivory and its demographic consequences}

Herbivore pressure from cactus-feeding insects varied systematically across elevation zones, a common finding in studies of herbivory across environmental gradients or between habitats (e.g., Louda 1982a, 1983, Smith 1987, Louda and Rodman 1996, Rand 1999, 2002, Sipura et al. 2002, Bradley et al. 2003, Maron and Kauffman 2006, Kolb et al. 2007). Cactus herbivores were most abundant and imposed the greatest damage in the low-elevation grassland and were least abundant and imposed the least damage at high elevation, on the rocky escarpment of the Los Pinos Mountains; this pattern was qualitatively consistent over four years (Fig. 2). Cactus density across the gradient was inversely related to the frequency and intensity of interactions with cactus-feeding insects (Figs. 1 and 2), implicating insect herbivory as a potential driver of variation in plant abundance.

The role of insect herbivory in the distribution of tree cholla abundance was further supported by our seedplanting experiment, in which we found that seedling recruitment and the degree of seed limitation (the difference in recruitment between levels of seed addition) were both greatest at low elevation (Fig. 3). These results were contrary to our prediction that seedling recruitment and seed limitation would be greatest at high elevation, based on the assumption that ambient plant density was an indicator of habitat suitability. Thus, the rarity of cacti in the low-elevation grassland did not appear to be driven by abiotic constraints on recruitment. In fact, the data suggest that conditions at low elevation were actually more suitable for tree cholla regeneration than elsewhere along the gradient (Table 2). While we report the results for only one year, we have conducted additional recruitment experiments in subsequent years and found a qualitatively similar pattern of variation (T. E. X. Miller, unpublished data). These additional experiments suggest that rodent activity plays a key role in this pattern: excluding rodents from seed addition plots leads to equivalent recruitment rates across elevation zones (T. E. X. Miller, unpublished data).

The AIC-based analyses of the demographic data identified substantial variation in key demographic functions across elevation zones and differential responses to insect exclusion across zones (Table 1). Medium-sized plants that were protected from herbivores experienced a small growth advantage over similarly sized plants exposed to herbivores, and this effect was greatest at low elevation (Fig. 5). For fecundity, we found the greatest positive response to insect exclusion in the largest plants, and this effect also was greatest at low elevation (Fig. 6). The effects of insect herbivory on individual growth and fecundity, together, led to impacts on population dynamics, estimated from integral projection models that were 

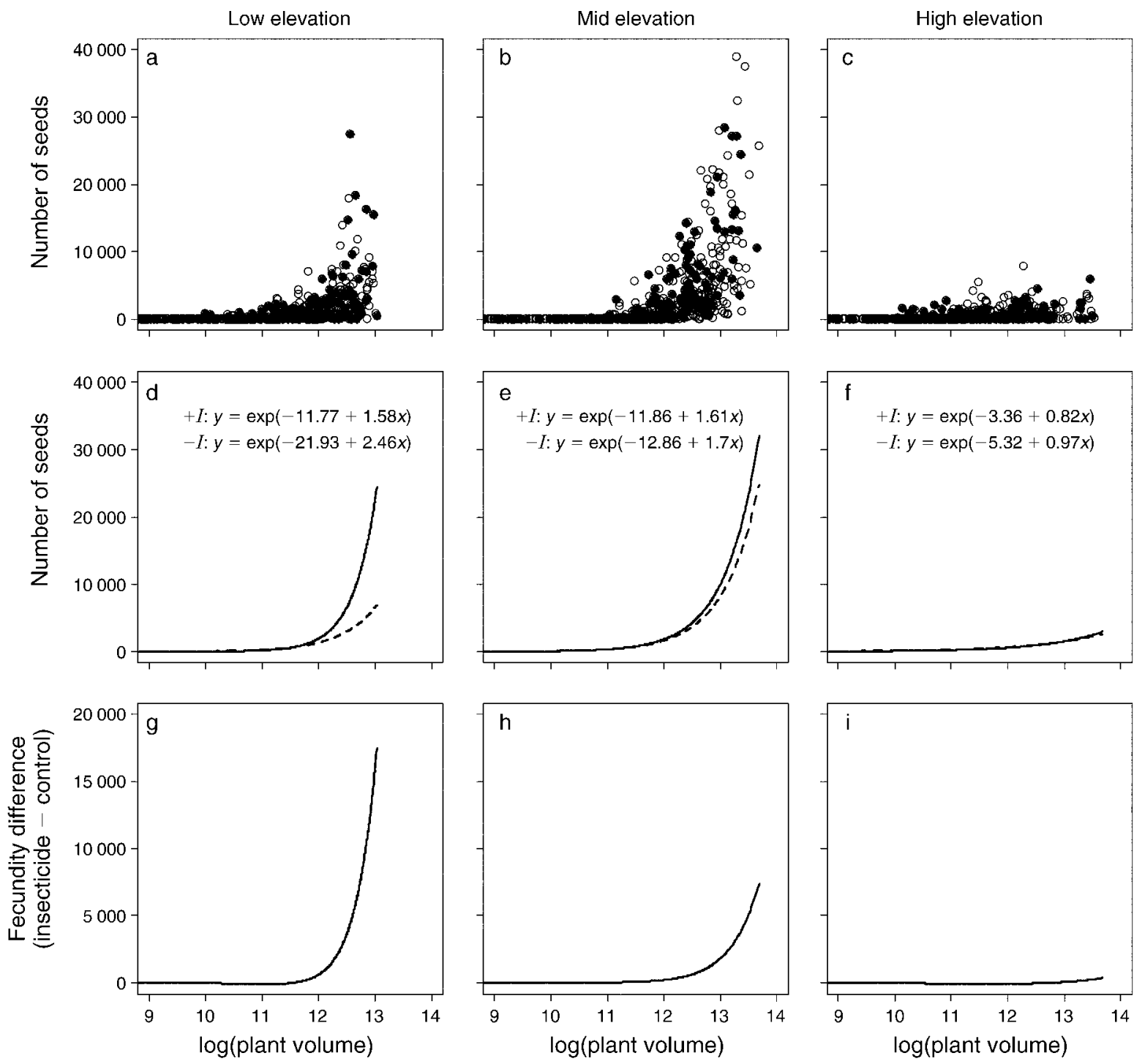

FIG. 6. Size-dependent seed production in tree cholla in relation to elevation zone and insect herbivory. (a-c) Experimental data and (d-f) fitted functions for the relationship between seed production and plant size for the low-, mid-, and high-elevation zones (open circles and dotted lines represent control; filled circles and solid lines represent insecticide treatment). Equations of fitted functions are given for each elevation zone under ambient $(+\mathrm{I})$ and reduced $(-\mathrm{I})$ insect herbivory. Panels $(\mathrm{g})-(\mathrm{i})$ show the difference between the fitted insecticide and control fecundity functions.

parameterized with the experimental field data (Table 4). The magnitude of the demographic effects of herbivory was spatially variable, highlighting the critical influence of environmental context on interaction outcome. We found that insect herbivory had the greatest effect on $\lambda$ at low elevation, where plants were least abundant and herbivory was most intense. The effect of herbivory on $\lambda$ was weaker at mid elevation and weakest at high elevation (Fig. 7), supporting our prediction of an inverse relationship between $\Delta \lambda$ and ambient plant density. The slightly negative effect of insect exclusion on $\lambda$ at high elevation was surprising, but we think this reflects random variation in the seed production data and fitted models (see Appendix D). We interpret from this result that tree cholla population growth was not influenced by insect herbivory at high elevation.

The results from our field experiments and demographic modeling provide strong support for the hypothesis that insect herbivory restricts the tree cholla

TABLE 4. Asymptotic rates of tree cholla population growth $(\lambda)$ at three positions along the elevational habitat gradient and under two experimental conditions (insect herbivores present or excluded with insecticide).

\begin{tabular}{lccc}
\hline \hline \multicolumn{1}{c}{ Condition } & Low & Mid & High \\
\hline Insects present & 1.041 & 1.136 & 0.985 \\
Insects excluded & 1.137 & 1.181 & 0.976 \\
\hline
\end{tabular}




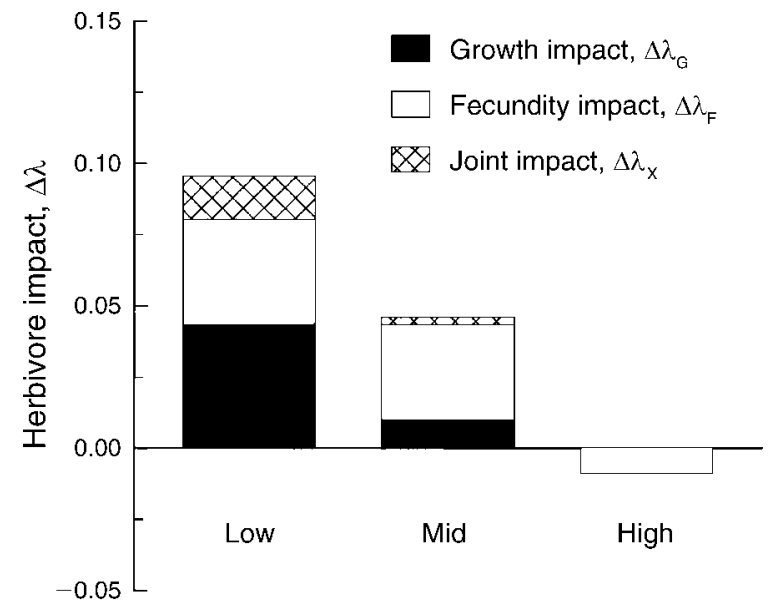

Elevation

FIG. 7. Effects of insect herbivory on tree cholla population growth. Bar heights show the total reduction in $\lambda$ due to insect herbivory $\left(\Delta \lambda=\lambda_{-}-\lambda_{+}\right)$in the low-, mid-, and high-elevation zones. Within each zone, the total effect is partitioned into the independent effects of herbivory on plant growth and fecundity and the joint, synergistic effect on both growth and fecundity.

distribution to a subset of suitable habitat across the heterogeneous desert landscape. Our work adds to a growing body of experimental literature that demonstrates a key role of herbivory in the spatial structure of plant populations (Louda 1982a, b, 1983, Smith et al. 1989, Louda and Rodman 1996, Rand 2002, Fine et al. 2004, Gomez 2005). From this literature, it is clear that variation in plant abundance across complex environmental gradients cannot be assumed to reflect constraints imposed only by abiotic factors or interspecific competition. Because the frequency, intensity, and demographic consequences of consumer-resource interactions can vary across environments and covary with (or counteract) key abiotic factors, context-dependent herbivory provides an alternative mechanism to explain patterns of distribution in plant abundances.

While clearly contributing to the pattern, it is unlikely that insect herbivory can fully explain the observed gradient-related variation in tree cholla density. There were clear differences in size-dependent fecundity and, to a lesser extent, growth and survival across elevation zones, indicating that additional factors, unrelated to insect herbivory, also differ among habitats and influence variation in tree cholla demography. In addition, exclusion of insect herbivores at low elevation did not cause a shift from decreasing $(\lambda<1)$ to increasing $(\lambda>1)$ population growth rates. Rather, populations at low elevation were predicted to increase even when insects were present, though at a much slower rate than when insects were excluded. At the other, high end of the gradient, where tree cholla was most abundant, populations were predicted to decline in both the presence and absence of insects. Thus, relative population growth rates were not reliable predictors of the observed variation in established plant density.

The maintenance of relatively high plant densities at high elevation, despite a deterministic prediction of population decline, may be explained by one or more factors. First, environmental stochasticity (e.g., recruitment pulses in unusually good years) may lead to greater population densities than expected under "average" conditions. Second, post-dispersal seed consumption by birds and rodents was greatest at high elevation, as indicated by our estimates of seed survival (Table 2) and additional vertebrate exclusion experiments (T. E. X. Miller, unpublished data). We assumed that all consumed seeds are destroyed, but it is likely that some seeds survive vertebrate gut passage with equal or perhaps greater germination probabilities as seeds that escape predation (Rojas-Arechiga and Vazquez-Yanes 2000). Third, a more persistent seed bank at high elevation could result in elevated population growth rates. Little is known about seed bank dynamics in the Cactaceae (Godinez-Alvarez et al. 2003). Montiel and Montana (2003), working with Opuntia rastrera in the Chihuahuan Desert, found that $1-2 \%$ of seed crops remained viable in the soil one year following dispersal. Interestingly, in 2005 and 2006, we observed recruitment from our 2004 seed additions in the high-elevation zone (T. E. X. Miller and S. Louda, unpublished manuscript), suggesting the potential for seed-banking in $O$. imbrica$t a$. These three factors, stochasticity in recruitment, seed survival following vertebrate consumption, and viable soil seed bank, may affect estimates of $\lambda$, but, based on our sensitivity analysis of seedling establishment (Appendix F), they should not alter the strength of the relative effects of herbivory documented across the gradient.

Another potential limitation of our modeling approach is that all demographic processes were assumed to be independent of population density. If intraspecific density dependence occurs anywhere in the life cycle, there could be a threshold of intensity below which herbivory does not reduce population growth (Harper 1977, Louda and Potvin 1995, Kauffman and Maron 2006). If so, density-independent models may overestimate the consequences of herbivory for population dynamics (Halpern and Underwood 2006, Maron and Crone 2006). However, seedling survival in the seed addition plots was unrelated to conspecific density in those plots ( $r=-0.087, P=0.37, n=103$ ). Also, while established plant performance was poorest at high elevation, where density was greatest, fecundity and survival were greatest at mid elevation, where density was only slightly lower. Further, we found no evidence of interspecific competition from grasses and forbs at the seedling and small juvenile stages, when mortality was greatest. Given the lack of evidence for strong intra- and interspecific density dependence, we think that the density-independent model provides a reasonable approximation to the dynamics of this population. 


\section{Factors that mediate herbivore effects on plant population dynamics}

It has been hypothesized that plant longevity and life history influence prediction of the effects of herbivory on plant populations. Short-lived perennial plants, reliant on current seed rain for regeneration, may be more vulnerable to population-level effects of herbivory than long-lived perennials (Louda 1989b, Louda and Potvin 1995, Maron and Gardner 2000, Maron and Crone 2006). In this study, the effects insect herbivory on the population growth of this long-lived perennial cactus were weaker in the low- and mid-elevation zones than effects reported for species with limited adult longevity (e.g., Shea and Kelly 1998, Parker 2000, Rose et al. 2005), but within the range reported for other longlived perennials (e.g., Ehrlen 1995, Garcia and Ehrlen 2002, Froborg and Eriksson 2003, Knight 2004). Thus, our results are consistent with the hypothesis that high adult survival and longevity can buffer plant populations against herbivore impacts. Interestingly, the effects of herbivory on tree cholla were also similar in magnitude to those observed on plants that are shortlived but maintain long-lived seed banks (reviewed in Maron and Crone 2006), suggesting that divergent plant storage strategies, whether above- or belowground, may be similarly effective in mediating the effects of herbivory.

The type of plant tissues targeted by herbivores could also mediate the consequences of plant-consumer interactions. We quantified the degrees to which herbivore effects on vegetative growth vs. reproductive success contributed to overall effects on population growth. We found that both types of damage were important, though their relative contributions varied spatially (Fig. 7). Reductions in the growth of mediumsized plants contributed to the overall effects of herbivory at low and mid elevation, despite the very small differences between the insecticide and control growth functions (Fig. 5). These results indicate that even seemingly weak effects of herbivores on individual plant growth can influence population dynamics by retarding the rate at which the population accumulates large individuals, which have the greatest reproductive potential. In contrast, the small reduction in growth due to herbivory at high elevation had no effect on population growth because seed production was much lower and more weakly size-dependent compared to the low- and mid-elevation zones (Fig. 6). Negative effects of herbivores on tree cholla fecundity also contributed to overall demographic effects (Fig. 7), despite the fact that seed production had far lower elasticity values than did stasis and growth (Appendix E). This finding is consistent with the suggestion that sensitivities and elasticities are poor predictors of the point in the life cycle at which herbivores can impose strong effects on population dynamics (Ehrlen 2003, Maron and Crone 2006).
Sources of spatial variation in cactus-insect interactions

The patterns of cactus herbivore abundance and damage across the gradient (Fig. 2) beg the question: why is herbivory so variable? Understanding the manner in which attributes of the biotic and abiotic environment influence plant-consumer interactions is important for predicting when and where herbivory may influence the distribution of plant abundance. Notably, the resource concentration hypothesis (Root 1973) cannot explain the pattern we observed (insect and plant abundances were inversely related), nor is there any clear evidence for roles of canopy cover, disturbance, or competition (Harper 1977, Gange et al. 1989, McEvoy and Coombs 1999, Maron et al. 2002). Rather, additional work in this system suggests spatial variation in ant-plant mutualism as a driver of variation in insect herbivory. Tree cholla secretes extrafloral nectar and is tended by two ant species at the Sevilleta NWR: Crematogaster opuntiae Buren and Liometopum apiculatum Mayr. The latter species provides effective biotic defense against cactusfeeding insects while the former is a poor defender (Miller 2007b). These two partner species replace one another across the gradient: Liometopum (the effective plant guard) is the most frequent ant on tree cholla at high elevation and Crematogaster (the poor plant guard) is most frequent at low elevation (Miller 2007c). Thus, we hypothesize that strong biotic defense by an effective mutualist at high elevation restricts insect herbivores and their effects on plant population growth to lower elevations and that this, in turn, influences the distribution of plant abundance across the gradient. This hypothesis parallels the results of Louda and Rodman (1996), who found that differences in levels of chemical defense led to greater herbivory and lower plant densities in sun vs. shade habitats. Further exploration of environmental influences on plant defense (chemical or biotic) as sources of variation in herbivore abundance and effects on host plants is merited.

\section{Inference for prediction of impacts by an invasive cactus-feeding insect}

Finally, our results provide some insight into the potential ecological effects of the invasive cactus-feeding moth, Cactoblastis cactorum Berg. This insect, native to Argentina, was intentionally redistributed throughout the world during the mid 20th century for the biological control of weedy Opuntia cacti (Pettey 1948, Zimmerman et al. 2001, 2004). It was unexpectedly discovered in Florida in 1989 (Habeck and Bennett 1990), and it has since spread north and west along the Gulf Coast, attacking native cacti (Johnson and Stiling 1998, Hight et al. 2002). With a wide host range within the genus Opuntia, including $O$. imbricata (Zimmerman et al. 2004), and suitable host plants distributed throughout the Gulf states and Texas, Cactoblastis is expected to invade Opuntia populations in the southwest United States and Mexico (Mahr 2001, Hight et al. 2002, Zimmerman et al. 2004, Simonson et al. 2005). 
Cactoblastis larvae feed within cactus pads and stem segments, often destroying these vegetative structures, reducing overall plant size and sometimes causing plant mortality (Dodd 1940, Pettey 1948, Mann 1969, Zimmerman et al. 2001). Our demographic results, which are consistent with those for other Opuntia species (e.g., Mandujano et al. 2001, Godinez-Alvarez et al. 2003), indicate that such individual-level damage has the potential of imposing negative effects on the population dynamics of the native cacti attacked, especially in combination with damage by the native cactus-feeding insects. The "pre-invasion" data presented here may be useful in quantitatively evaluating the ecological effects of Cactoblastis if this invasive herbivore reaches the Opuntia populations of the Chihuahuan Desert.

\section{ACKNOWLEDGMENTS}

We are grateful for the valuable logistical support provided by the Sevilleta LTER (especially Jennifer Johnson and Scott Collins) and the Sevilleta National Wildlife Refuge (especially Renee Robichaud and Dennis Pritchard). The use of insecticide was in compliance with U.S. Fish and Wildlife Service guidelines (Special Use Permit number 2003029). Diana Pilson, Kathleen Keeler, Brian Inouye, Nora Underwood, and an anonymous reviewer provided helpful comments on this manuscript. This research was funded by the Initiative for Ecological and Evolutionary Analysis at the University of Nebraska-Lincoln and the Sevilleta LTER (NSF DEB0217774). T. E. X. Miller was supported by a U.S. Department of Education graduate fellowship (Graduate Assistance in Areas of National Need) while conducting the research and a USDA postdoctoral fellowship (National Research Initiative 2007-02270) while preparing the manuscript. Finally, we acknowledge the scholarship of John Mann, whose monograph on cactus insects was an invaluable resource in the development of this project.

\section{Literature Cited}

Agrawal, A. A., et al. 2007. Filling key gaps in population and community ecology. Frontiers in Ecology and the Environment 5:145-152.

Bastrenta, B., J.-D. Lebreton, and J. D. Thompson. 1995. Predicting demographic change in response to herbivory: a model of the effects of grazing and annual variation on the population dynamics of Anthyllis vulneraria. Journal of Ecology 83:603-611.

Benson, L. 1982. Cacti of the United States and Mexico. Stanford University Press, Stanford, California, USA.

Bevill, R. L., S. M. Louda, and L. M. Stanforth. 1999. Protection from natural enemies in managing rare plant species. Conservation Biology 13:1323-1331.

Bigger, D. S., and M. A. Marvier. 1998. How different would a world without herbivory be? A search for generality in ecology. Integrated Biology 1:60-67.

Bowers, J. E. 1996. More flowers or new cladodes? Environmental correlates and biological consequences of sexual reproduction in a Sonoran Desert prickly pear cactus, Opuntia engelmannii. Bulletin of the Torrey Botanical Club 123:34-40.

Bradley, K. L., E. I. Damschen, L. M. Young, D. Duefler, S. Went, G. Wray, N. M. Haddad, J. M. H. Knops, and S. M. Louda. 2003. Spatial heterogeneity, not visitation bias, dominates variation in herbivory. Ecology 84:2214-2221.

Burnham, K. P., and D. R. Anderson. 2002. Model selection and multimodel inference: a practical information-theoretic approach. Second edition. Springer, New York, New York, USA.
Caswell, H. 2001. Matrix population models. Sinauer, Sunderland, Massachusetts, USA.

Crawley, M. J. 1989. Insect herbivores and plant population dynamics. Annual Review of Entomology 34:531-564.

Crawley, M. J. 1990. The population dynamics of plants. Philosophical Transactions of the Royal Society B 330: $125-140$.

Crawley, M. J. 1997. Plant-herbivore dynamics. Pages 401-474 in M. J. Crawley, editor. Plant ecology. Blackwell Science, Oxford, UK.

Denno, R. F., and M. S. McClure. 1983. Variable plants and herbivores in natural and managed systems. Academic Press, New York, New York, USA.

Doak, D. F. 1992. Lifetime impacts of herbivory for a perennial plant. Ecology 73:2086-2099.

Dodd, A. P. 1940. The biological campaign against prickly pear. Commonwealth Prickly Pear Board, Brisbane, Queensland, Australia.

Easterling, M. R., S. P. Ellner, and P. M. Dixon. 2000. Sizespecific sensitivity: applying a new structured population model. Ecology 81:694-708.

Ehrlen, J. 1995. Demography of the perennial herb Lathyrus vernus. II. Herbivory and population dynamics. Journal of Ecology 83:297-308.

Ehrlen, J. 2003. Fitness components versus total demographic effects: evaluating herbivore impacts on a perennial herb. American Naturalist 162:796-810.

Ehrlich, P. R., and L. C. Birch. 1967. The 'balance of nature' and 'population control.' American Naturalist 101:97-107.

Ellner, S. P., and M. Rees. 2006. Integral projection models for species with complex demography. American Naturalist 167: $410-428$.

Fagan, W. F., and J. G. Bishop. 2000. Trophic interactions during primary succession: herbivores slow a plant reinvasion at Mount St. Helens. American Naturalist 155:238-251.

Fagan, W. F., M. A. Lewis, M. G. Neubert, C. Aumann, J. L. Apple, and J. G. Bishop. 2005. When can herbivores slow or reverse the spread of an invading plant? A test case from Mount St. Helens. American Naturalist 166:669-685.

Fine, P. V. A., I. Mesones, and P. D. Coley. 2004. Herbivores promote habitat specialization by trees in Amazonian forests. Science 305:663-665.

Froborg, H., and O. Eriksson. 2003. Predispersal seed predation and population dynamics in the perennial understory herb Actea spicata. Canadian Journal of Botany 81: $1058-1069$

Gange, A. C., V. K. Brown, I. M. Evans, and A. L. Storr. 1989. Variation in the impact of insect herbivory on Trifolium pratense through early plant succession. Journal of Ecology 77:537-551.

Garcia, M. B., and J. Ehrlen. 2002. Reproductive effort and herbivory timing in a perennial herb: fitness components at the individual and population levels. American Journal of Botany 89:1295-1302.

Godinez-Alvarez, H., T. Valverde, and P. Ortega-Baes. 2003. Demographic trends in the Cactaceae. Botanical Review 69: 173-203.

Gomez, J. M. 2005. Long-term effects of ungulates on performance, abundance, and spatial distribution of two montane herbs. Ecological Monographs 75:231-258.

Habeck, D. H., and F. D. Bennett. 1990. Cactoblastis cactorum Berg (Lepidoptera: Pyralidae), a phycitine new to Florida. Entomology Circular 333. Florida Department of Agriculture and Consumer Services, Division of Plant Industries, Gainesville, Florida, USA.

Hairston, N. G., F. E. Smith, and L. B. Slobodkin. 1960. Community structure, population control, and competition. American Naturalist 94:421-425.

Halpern, S. L., and N. Underwood. 2006. Approaches for testing herbivore effects on plant population dynamics. Journal of Applied Ecology 43:922-929. 
Harper, J. L. 1977. The population biology of plants. Academic Press, New York, New York, USA.

Hight, S. D., J. E. Carpenter, K. A. Bloem, R. W. Pemberton, and P. Stiling. 2002. Expanding geographic range of Cactoblastis cactorum (Lepidoptera: Pyralidae) in North America. Florida Entomologist 85:527-529.

Johnson, D. M., and P. D. Stiling. 1998. Distribution and dispersal of Cactoblastis cactorum (Lepidoptera: Pyralidae), an exotic Opuntia-feeding moth, in Florida. Florida Entomologist 81:12-22.

Kauffman, M. J., and J. L. Maron. 2006. Consumers limit the abundance and dynamics of a perennial shrub with a seed bank. American Naturalist 168:454-470.

Kelly, C. A., and R. J. Dyer. 2002. Demographic consequences of inflorescence-feeding insects for Liatris cylindracea, an iteroparous perennial. Oecologia (Berlin) 132:350-360.

Knight, T. M. 2004. The effects of herbivory and pollen limitation on a declining population of Trillium grandiflorum. Ecological Applications 14:915-928.

Kolb, A., R. Leimu, and J. Ehrlen. 2007. Environmental context influences the outcome of a plant-seed predator interaction. Oikos 116:864-872.

Lau, J. A., and S. Y. Strauss. 2005. Insect herbivores drive important indirect effects of exotic plants on native communities. Ecology 86:2990-2997.

Louda, S. M. 1982a. Distribution ecology: variation in plant recruitment in relation to insect seed predation. Ecological Monographs 52:25-41.

Louda, S. M. 1982b. Limitation of the recruitment of the shrub Haplopappus squarrosus (Asteraceae) by flower- and seedfeeding insects. Journal of Ecology 70:43-53.

Louda, S. M. 1983. Seed predation and seedling mortality in the recruitment of a shrub, Haplopappus venetus (Asteraceae), along a climatic gradient. Ecology 64:511-521.

Louda, S. M. 1989a. Differential predation pressure: A general mechanism for structuring plant communities along complex environmental gradients? Trends in Ecology and Evolution 4: $158-159$.

Louda, S. M. 1989b. Predation in the dynamics of seed regeneration. Pages 25-51 in M. A. Leck, V. T. Parker, and R. L. Simpson, editors. Ecology of soil seed banks. Academic Press, New York, New York, USA.

Louda, S. M., P. M. Dixon, and N. J. Huntly. 1987. Herbivory in sun and shade at a natural meadow-woodland ecotone in the Rocky Mountains. Vegetatio 72:141-149.

Louda, S. M., K. H. Keeler, and R. Holt. 1990. Herbivore influences on plant performances and competitive interactions. Pages 414-444 in J. B. Grace and D. Tilman, editors. Perspective on plant competition. Academic Press, San Diego, California, USA.

Louda, S. M., and M. A. Potvin. 1995. Effect of inflorescencefeeding insects in the demography and lifetime fitness of a native plant. Ecology 76:229-245.

Louda, S. M., T. A. Rand, A. E. Arnett, A. S. McClay, K. Shea, and A. K. McEachern. 2005. Evaluation of ecological risk to populations of a threatened plant from an invasive biocontrol insect. Ecological Applications 15:234-249.

Louda, S. M., and J. E. Rodman. 1996. Insect herbivory as a major factor in the shade distribution of a native crucifer (Cardamine cordifolia A. Gray, bittercress). Journal of Ecology 84:229-238.

Mahr, D. L. 2001. Cactoblastis cactorum (Lepidoptera: Pyralidae) in North America: a workshop of assessment and planning. Florida Entomologist 84:465-473.

Mandujano, M. C., C. Montana, M. Franco, J. Golubov, and A. Flores-Martinez. 2001. Integration of demographic annual variability in a clonal desert cactus. Ecology 82: 344-359.

Mann, J. 1969. Cactus-feeding insects and mites. Smithsonian Institution, Washington, D.C., USA.
Maron, J. L., J. K. Combs, and S. M. Louda. 2002. Convergent demographic effects of insect attack on related thistles in coastal vs. continental dunes. Ecology 31:3382-3392.

Maron, J. L., and E. Crone. 2006. Herbivory: effects on plant abundance, distribution, and population growth. Proceedings of the Royal Society B 273:2575-2584.

Maron, J. L., and S. N. Gardner. 2000. Consumer pressure, seed versus safe-site limitation, and plant population dynamics. Oecologia 124:260-269.

Maron, J. L., and M. J. Kauffman. 2006. Habitat-specific impacts of multiple consumers on plant population dynamics. Ecology 87:113-124.

McEvoy, P. B., and E. M. Coombs. 1999. Biological control of plant invaders: regional patterns, field experiments, and structured population models. Ecological Applications 9: 387-401.

McEvoy, P. B., N. T. Rudd, C. S. Cox, and M. Huso. 1993. Disturbance, competition, and herbivory effects on ragwort Senecio jacabaea populations. Ecological Monographs 63: $55-75$.

McFarland, J. D., P. G. Kevan, and M. A. Lane. 1989. Pollination biology of Opuntia imbricata (Cactaceae) in southern Colorado. Canadian Journal of Botany 67:24-28.

Miller, T. E. X. 2007a. Demographic models reveal the shape of density dependence for a specialist herbivore on variable host-plants. Journal of Animal Ecology 76:722-729.

Miller, T. E. X. 2007b. Does having multiple partners weaken the benefits of facultative mutualism? A test with cacti and cactus-tending ants. Oikos 116:500-512.

Miller, T. E. X. 2007c. Interactions between cacti and cactusfeeding insects: causes and consequences of variation. Dissertation. University of Nebraska, Lincoln, Nebraska, USA.

Miller, T. E. X. 2008. Top-down, bottom-up, and withintrophic level pressures on a cactus-feeding insect. Ecological Entomology 33:261-268.

Miller, T. E. X., B. Tenhumberg, and S. M. Louda. 2008. Herbivore-mediated ecological costs of reproduction shape the life history of an iteroparous plant. American Naturalist 171:141-149.

Miller, T. E. X., A. J. Tyre, and S. M. Louda. 2006. Plant reproductive allocation predicts herbivore dynamics across spatial and temporal scales. American Naturalist 168:608616.

Montiel, S., and C. Montana. 2003. Seed bank dynamics of the desert cactus Opuntia rastrera in two habitats from the Chihuahuan Desert. Plant Ecology 166:241-248.

Moran, V. C. 1980. Interactions between phytophagous insects and their Opuntia hosts. Ecological Entomology 5:153-164.

Parker, I. M. 2000. Invasion dynamics of Cytisus scoparius: a matrix model approach. Ecological Applications 10:726-743.

Pettey, F. W. 1948. The biological control of prickly pear in South Africa. Department of Agriculture of the Union of South Africa Science Bulletin 261:1-163.

Pickett, C. H., and W. D. Clark. 1979. The function of extrafloral nectaries in Opuntia acanthocarpa (Cactaceae). American Journal of Botany 66:618-625.

R Development Core Team. 2008. R: A language and environment for statistical computing. R Foundation for Statistical Computing, Vienna, Austria. 〈http://www. R-project.org $\rangle$

Ramula, S., and K. Lehtila. 2005. Matrix dimensionality in demographic analyses of plants: When to use smaller matrices? Oikos 111:563-573.

Rand, T. A. 1999. Effects of environmental context on the susceptibility of Atriplex patula to attack by herbivorous beetles. Oecologia 121:39-46.

Rand, T. A. 2002. Variation in insect herbivory across a salt marsh tidal gradient influences plant survival and distribution. Oecologia (Berlin) 132:549-558. 
Rojas-Arechiga, M., and C. Vazquez-Yanes. 2000. Cactus seed germination: a review. Journal of Arid Environments 44: 85-104.

Root, R. 1973. Organization of a plant-arthropod association in simple and diverse habitats: the fauna of collards. Ecological Monographs 43:95-124.

Root, R. B., and N. Cappuccino. 1992. Patterns in population change and the organization of the insect community associated with goldenrod. Ecological Monographs 63: 393-420.

Rose, K. E., S. M. Louda, and M. Rees. 2005. Demographic and evolutionary impacts of native and invasive insect herbivores: a case study with Platte thistle, Cirsium canescens. Ecology 86:453-465.

Shea, K., and D. Kelly. 1998. Estimating biocontrol agent impact with matrix models: Carduus nutans in New Zealand. Ecological Applications 8:824-832.

Silvertown, J., M. Franco, I. Pisanty, and A. Mendoza. 1993. Comparative plant demography: relative importance of lifecycle components to the finite rate of increase in woody and herbaceous perennials. Journal of Ecology 81:465-476.

Simonson, S. E., T. J. Stohlgren, L. Tyler, W. P. Gregg, R. Muir, and L. J. Garrett. 2005. Preliminary assessment of the potential impacts and risks of the invasive cactus moth, Cactoblastis cactorum Berg, in the U.S. and Mexico. International Atomic Energy Agency, Vienna, Austria.

Sipura, M., A. Ikonen, J. Tahnanainen, and H. Roininen. 2002. Why does the leaf beetle Galerucella lineola F. attack wetland willows? Ecology 83:3393-3407.

Smith, T. J., III. 1987. Seed predation in relation to tree dominance and distribution in mangrove forests. Ecology 68: 266-273.
Smith, T. J., III, H.-T. Chan, C. C. McIvor, and M. B. Robblee. 1989. Inter-continental comparisons of seed predation in tropical, tidal forests. Ecology 70:146-151.

Stiling, P., D. Moon, and D. Gordon. 2004. Endangered cactus restoration: mitigating the non-target effects of a biological control agent (Cactoblastis cactorum) in Florida. Restoration Ecology 12:605-610.

Strauss, S. Y., and A. Zangerl. 2002. Plant-insect interactions in terrestrial ecosystems. Pages 77-106 in C. M. Herrera and O. Pellmyr, editors. Plant-animal interactions: an evolutionary approach. Blackwell Sciences, Oxford, UK.

Strong, D. R., J. H. Lawton, and T. R. E. Southwood. 1984. Insects on plants: community patterns and mechanisms. Blackwell Scientific, Oxford, UK.

USDA [U.S. Department of Agriculture]. 1989. Soil survey of Socorro County area, New Mexico. U.S. Department of Agriculture Soil Conservation Service, Albuquerque, New Mexico, USA.

Warner, P. J., and J. H. Cushman. 2002. Influence of herbivores on a perennial plant: variation with life-history stage and herbivore species. Oecologia 132:77-85.

Zimmerman, H. G., S. Bloem, and H. Klein. 2004. Biology, history, threat, surveillance and control of the cactus moth, Cactoblastis cactorum. Pages 1-40 in Proceedings: Joint FAO/IAEA Programme of Nuclear Techniques in Food and Agriculture. International Atomic Energy Agency, Vienna, Austria.

Zimmerman, H. G., V. C. Moran, and J. H. Hoffmann. 2001. The renowned cactus moth, Cactoblastis cactorum (Lepidoptera: Pyralidae): its natural history and threat to native Opuntia floras in Mexico and the United States of America. Florida Entomologist 84:543-551.

\section{APPENDIX A}

Elevational gradient at Sevilleta National Wildlife Refuge, New Mexico, USA (Ecological Archives M079-005-A1).

\section{APPENDIX B}

Direct effects of insecticide on plant performance (Ecological Archives M079-005-A2).

APPENDIX C

Effects of water addition on plant performance (Ecological Archives M079-005-A3).

\section{APPENDIX D}

Rescaled view of high-elevation seed production data (Ecological Archives M079-005-A4).

\section{APPENDIX E}

Elasticities of cactus population growth rate $(\lambda)$ to variation in demographic transitions (Ecological Archives M079-005-A5).

\section{APPENDIX F}

Sensitivity analyses of integral projection model (IPM) predictions to variation in parameter estimates (Ecological Archives M079-005-A6).

\section{APPENDIX G}

Interannual variation in estimates of population growth (Ecological Archives M079-005-A7) 
Tom E. X. Miller, Svata M. Louda, Karen A. Rose, and James O. Eckberg. 2009. Impacts of insect herbivory on cactus population dynamics: experimental demography across an environmental gradient. Ecological Monographs 79:155-172.

Appendix A. Elevational gradient at Sevilleta National Wildlife Refuge.

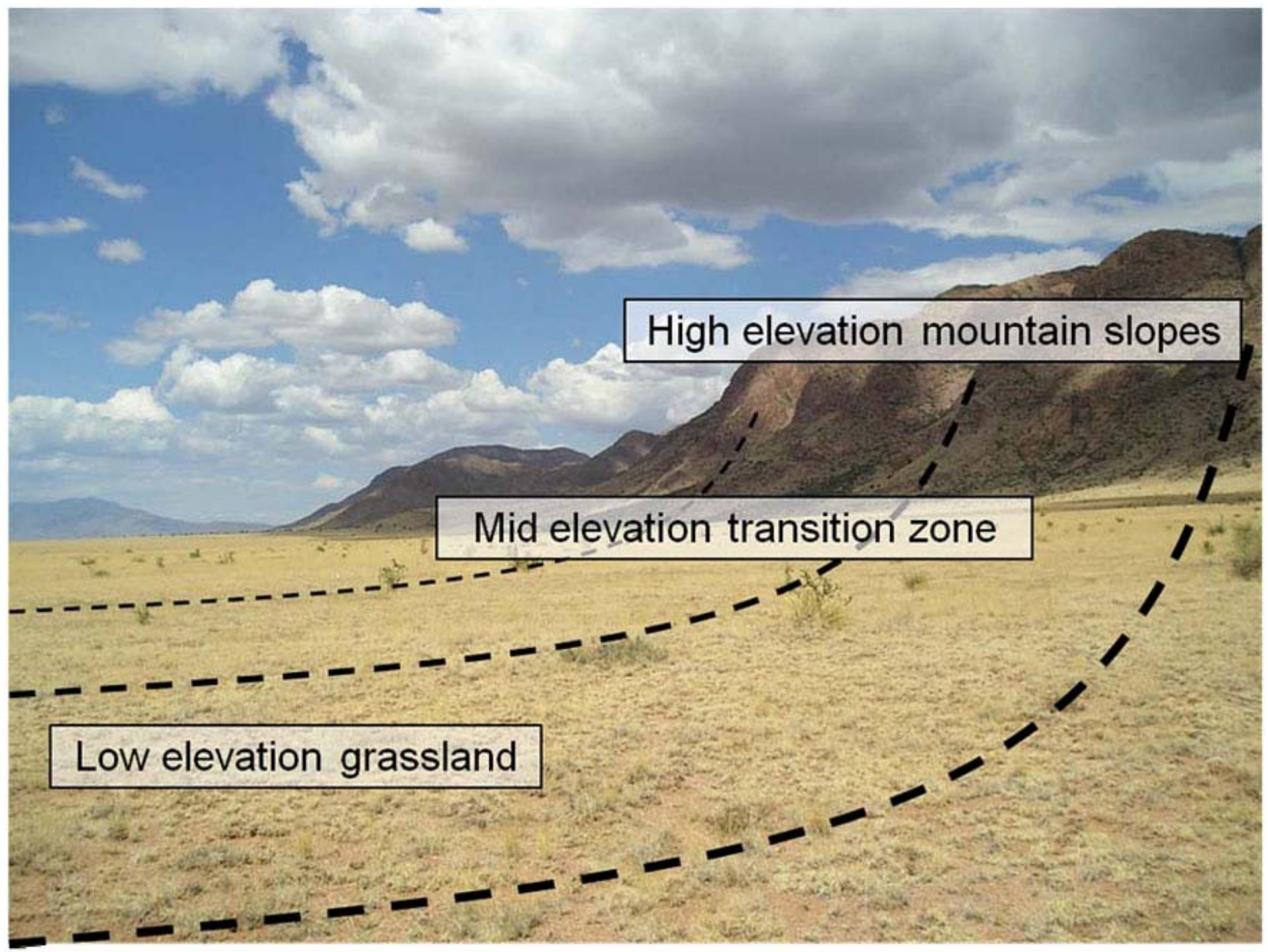

FIG. A1. Study area at Sevilleta National Wildlife Refuge, New Mexico, USA. Dotted lines represent transects used to replicate effects of elevation zone (lines not to scale). 


\section{Tom E. X. Miller, Svata M. Louda, Karen A. Rose, and James O. Eckberg. 2009. Impacts of insect herbivory on cactus population dynamics: experimental demography across an environmental gradient. Ecological Monographs 79:155-172.}

Appendix B. Direct effects of insecticide on plant performance.

We conducted an experiment to determine if insecticide (carbaryl) application had any direct (beneficial or phytotoxic) effects on plant performance. In 2005, we transplanted 20 tree cholla ( $0.5 \mathrm{~m}$ height) into pots directly from our field site and brought these plants into a greenhouse at the Sevilleta NWR. We measured the lengths of all new stem segments initiated by each plant on May 21. Potted plants were then randomly assigned to insecticide or water treatments, and these treatments were applied every two weeks throughout the 2005 growing season (synchronized with the field experiment). We measured stem segments again on September 6. For each plant, we summed lengths over all stem segments and measured relative growth as the difference between finial and initial total stem segment length, divided by the initial value.

We found that growth in the greenhouse, where all plants were protected from herbivores, was similar between insecticide and water treatments (mean [SEM] insecticide: 4.37 [0.91], control: 5.69 [1.23]) and did not differ statistically between treatments $\left(t_{18}=0.86, P=0.39\right)$. We conclude that application of carbaryl had no measurable, un-intended effects on plant growth. 


\section{Ecological Archives M079-005-A3}

\section{Tom E. X. Miller, Svata M. Louda, Karen A. Rose, and James O. Eckberg. 2009. Impacts of insect herbivory on cactus population dynamics: experimental demography across an environmental gradient. Ecological Monographs 79:155-172.}

Appendix C. Effects of water addition on plant performance.

We used two control treatments (dry control, water control) for the adult plants in the insect exclusion experiment to determine if the small amount of water applied with insecticide in the dry environment had any effects on plant performance or herbivory. We examined the difference in herbivore damage (described under Methods) between the two control treatments using repeated-measures ANOVA, with treatment (dry control, water control), zone (low, mid, high), and year (2004, 2005, 2006) as fixed effects, and transect as a random effect. We also examined whether water addition influenced vegetative growth. In May 2004, we measured the lengths $(\mathrm{cm})$ of all newly produced stem segments on two randomly selected segment clusters on each plant. We marked these clusters, and re-measured them in September 2004. We summed the segment lengths for each plant on each sampling date and calculated relative growth rate (RGR) as the difference between final and initial total length, divided by the initial value. We used ANOVA to test for a difference in RGR between water and dry control treatments across elevation zones, with transect as a random effect. Plants in the insecticide treatment group were not included in these analyses.

Herbivore damage was not influenced by water addition in any elevation zone or in any year of the experiment, as indicated by nonsignificant effects of treatment $\left(F_{1,503}=0.03, P=0.87\right)$, treatment $\times$ zone $\left(F_{2,503}=0.84, P=0.43\right)$, treatment $\times$ year $\left(F_{2,503}=0.9, P=0.4\right)$, and the three-way interaction $\left(F_{1,503}=1.7, P=0.14\right)$. We found the same result for relative growth rate in 2004, with no significant effects of treatment $\left(F_{1,170}=0.17, P=0.68\right)$ or treatment $\times$ zone $\left(F_{2,170}=1.72, P=0.18\right)$. We conclude that the application of small amounts of water had no effects on herbivory or plant performance, and so did not confound interpretation of our insecticide treatment. 
Tom E. X. Miller, Svata M. Louda, Karen A. Rose, and James O. Eckberg. 2009. Impacts of insect herbivory on cactus population dynamics: experimental demography across an environmental gradient. Ecological Monographs 79:155-172.

Appendix D. Rescaled view of high-elevation seed production data.
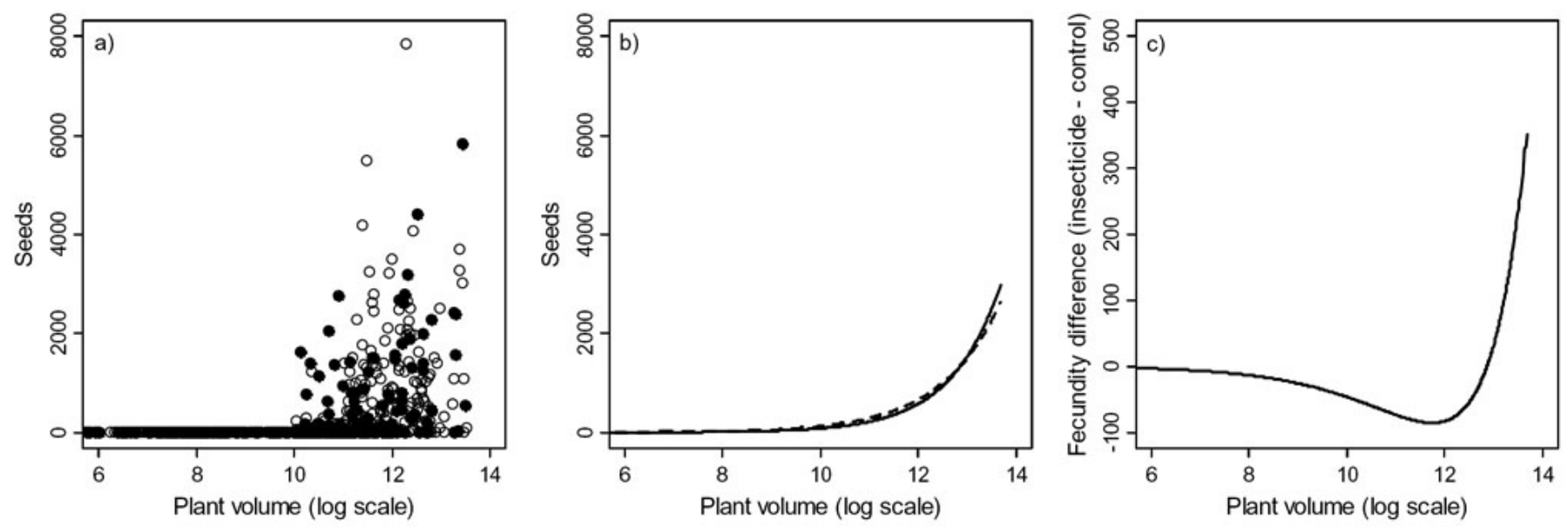

FIG. D1. Effects of insect herbivory on seed production by tree cholla cacti in the high elevation zone (rescaled view of Figs. 6c,f,i). This figure shows estimated seed production (a) and fitted functions (b) for plants that were sprayed with insecticide (black circles / solid line) or exposed to insect herbivory as control (open circles / dashed line), and the difference between the two fitted functions (c, insecticide - control). Note the predicted negative effect of insecticide on seed production for an intermediate section of the size distribution. 
Tom E. X. Miller, Svata M. Louda, Karen A. Rose, and James O. Eckberg. 2009. Impacts of insect herbivory on cactus population dynamics: experimental demography across an environmental gradient. Ecological Monographs 79:155-172.

Appendix E. Elasticities of cactus population growth rate $(\lambda)$ to variation in demographic transitions.

a) Low elevation

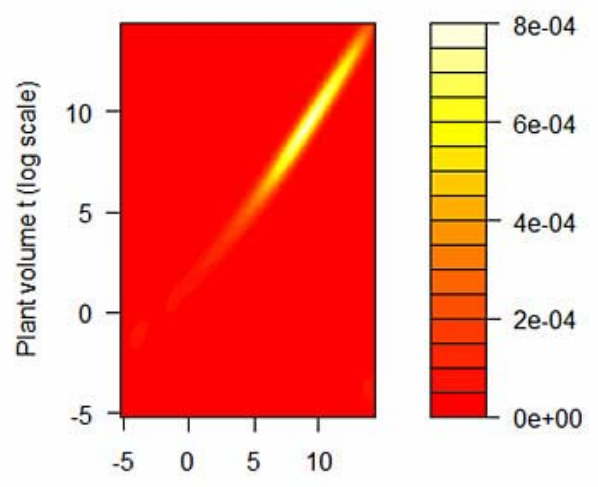

Plant volume $\mathrm{t}+1$ (log scale) b) Mid elevation

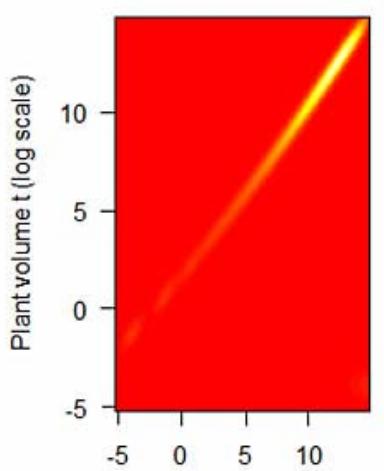

Plant volume $\mathrm{t}+1$ (log scale)

c) High elevation
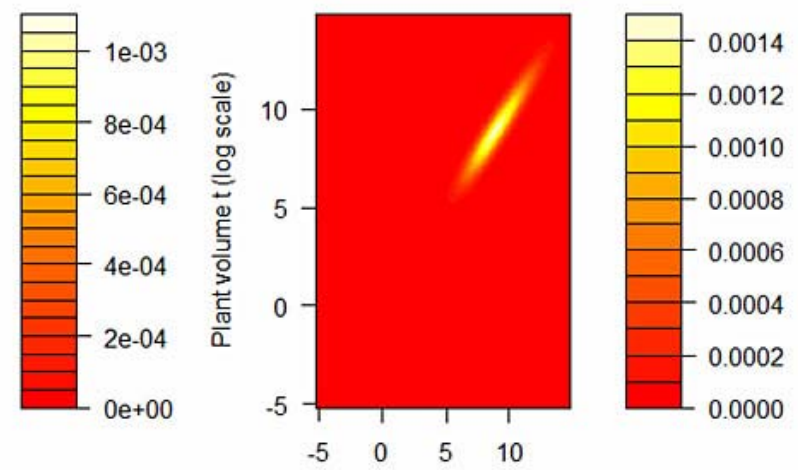

Plant volume $t+1$ (log scale)

FIG. E1. Elasticity surfaces of the control IPM kernels each elevation zone. Plots show all possible demographic transitions between current and future size, and the effect on $\lambda$ of proportional changes at all points of the surface (coded by color). Diagonal streaks in the upper-right corners correspond to stasis of large individuals. 
Tom E. X. Miller, Svata M. Louda, Karen A. Rose, and James O. Eckberg. 2009. Impacts of insect herbivory on cactus population dynamics: experimental demography across an environmental gradient. Ecological Monographs 79:155-172.

Appendix F. Sensitivity analyses of integral projection model (IPM) predictions to variation in parameter estimates.

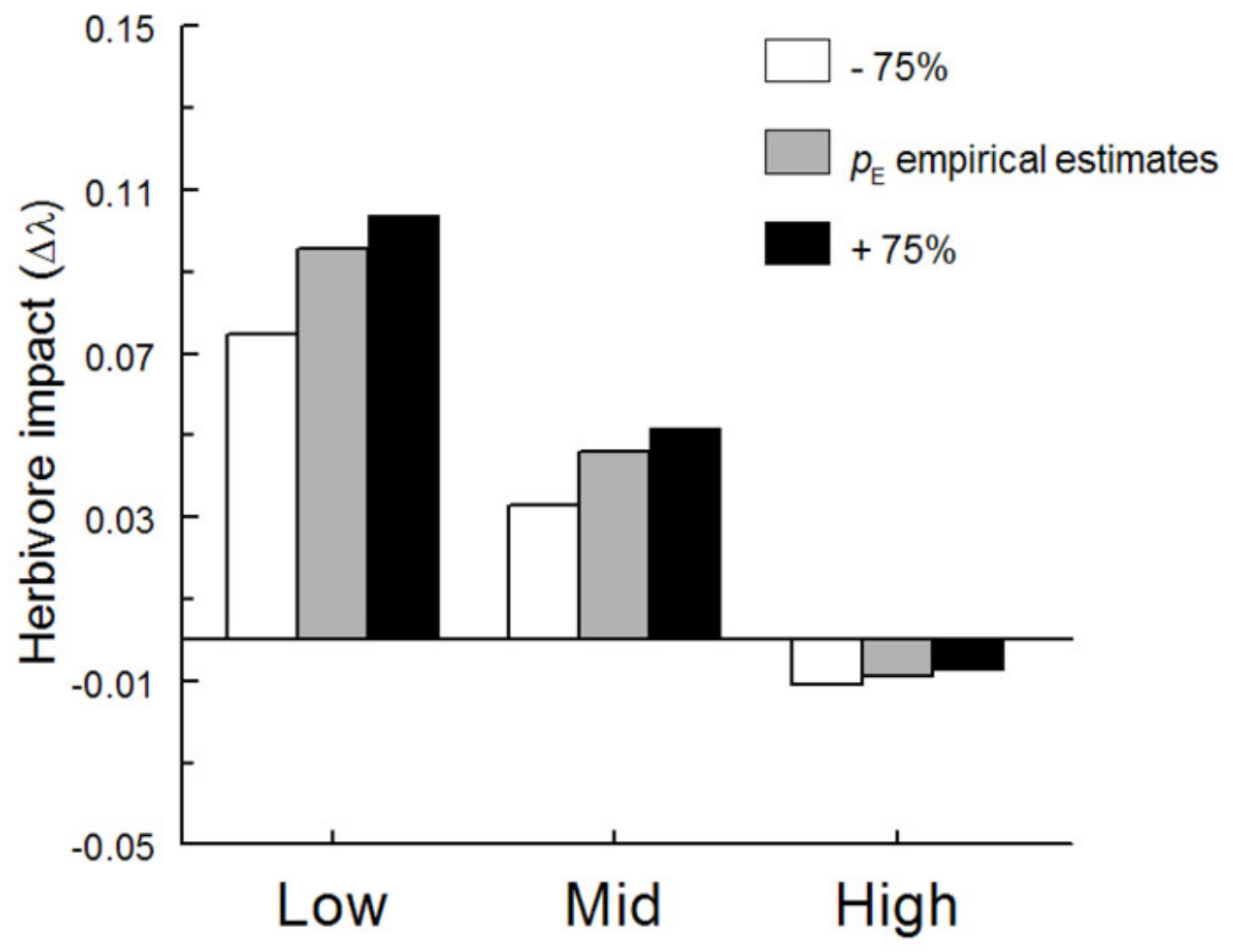

FIG. F1. Spatial variation in the effects of insect herbivory on cactus population growth, and sensitivity of herbivore effect to variation in the probability of seedling establishment $(p \mathrm{E})$. Gray bars show results based on the empirical estimates given in Table 2, and white and black bars show results based on a 75\% decrease or increase in those values. 


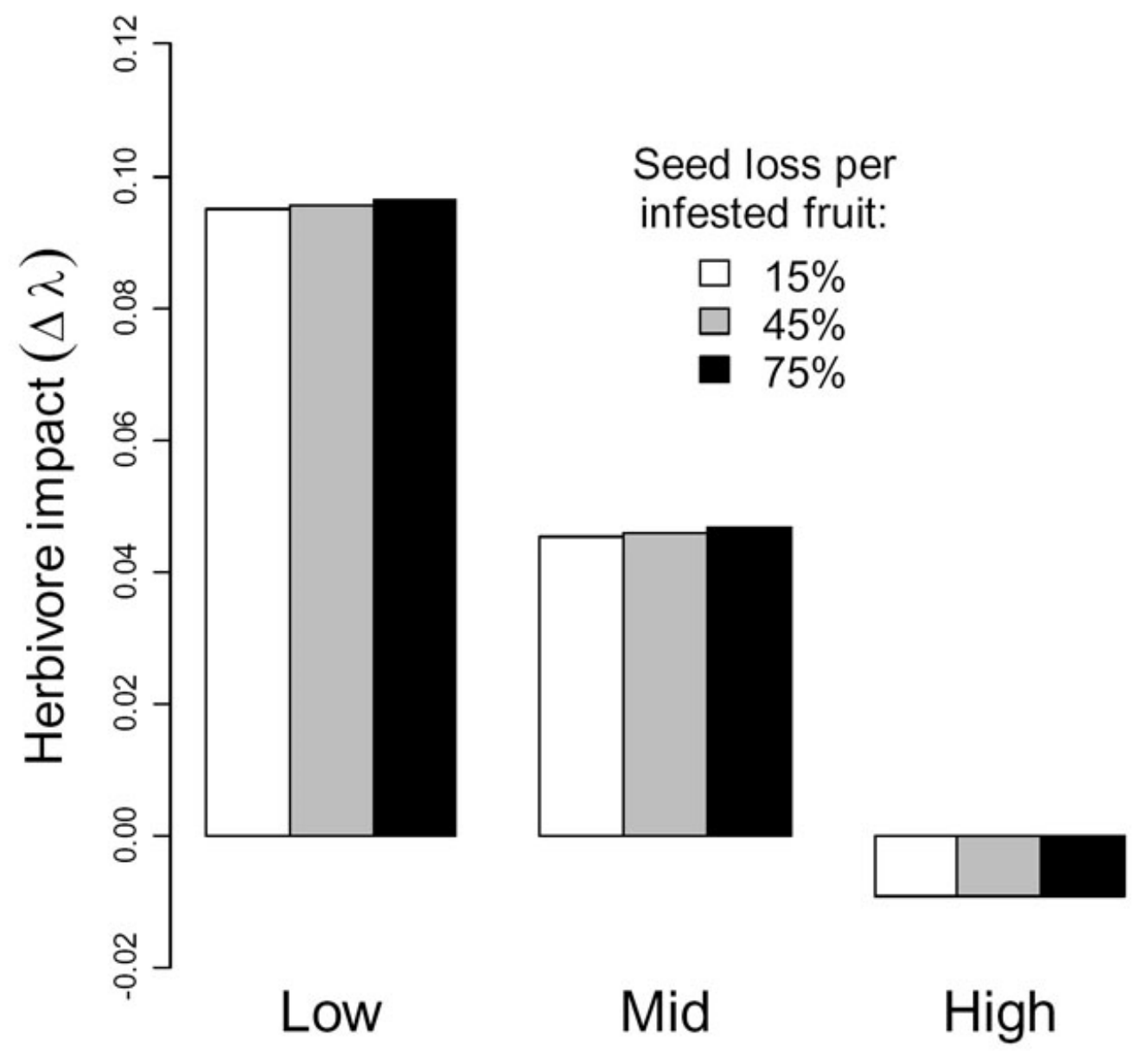

FIG. F2. Spatial variation in the effects of insect herbivory on cactus population growth, and sensitivity of herbivore effect to variation in damage caused by Cahela ponderosella, the pre-dispersal seed predator. Gray bars show results based on the best empirical estimate of Cahela damage (45\% of seeds eaten per infested fruit). White and black bars show predictions for lower and greater levels of moth damage (15\% and $75 \%$ of seeds eaten per infested fruit). 
Tom E. X. Miller, Svata M. Louda, Karen A. Rose, and James O. Eckberg. 2009. Impacts of insect herbivory on cactus population dynamics: experimental demography across an environmental gradient. Ecological Monographs 79:155-172.

Appendix G. Interannual variation in estimates of population growth.

TABLE G1. Estimates of cactus population growth $(\lambda)$ in three elevation zones (low, mid, high) based on three interannual transitions for which we collected demographic data (2004-2005, 2005-2006, 2006-2007).

\begin{tabular}{|c|c|c|c|c|}
\hline \multirow{4}{*}{ Insects present } & & Low & Mid & High \\
\hline & 2004-2005 & 1.0944 & 1.1339 & 0.9930 \\
\hline & $2005-2006$ & 1.1008 & 1.1605 & 0.9845 \\
\hline & 2006-2007 & 1.0454 & 1.2286 & 0.9800 \\
\hline \multirow{3}{*}{ Insects excluded } & 2004-2005 & 1.1911 & 1.1761 & 0.9876 \\
\hline & 2005-2006 & 1.1498 & 1.1977 & 0.9748 \\
\hline & 2006-2007 & 1.0663 & 1.2385 & 0.9704 \\
\hline
\end{tabular}

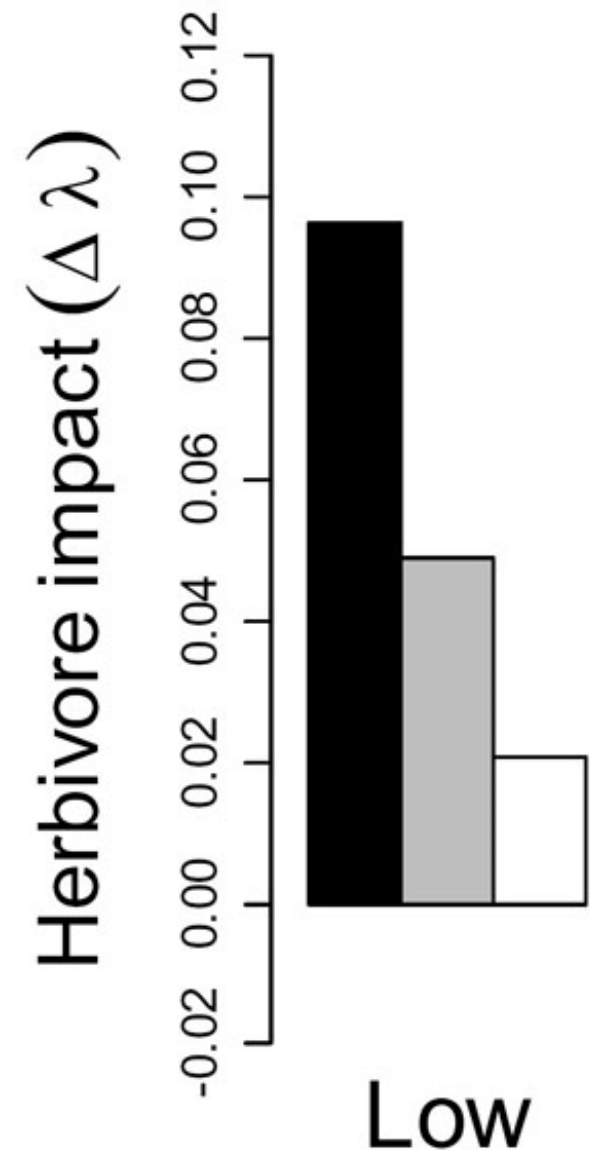

\section{- 2004-2005 $\square$ 2005-2006 $\square$ 2006-2007}
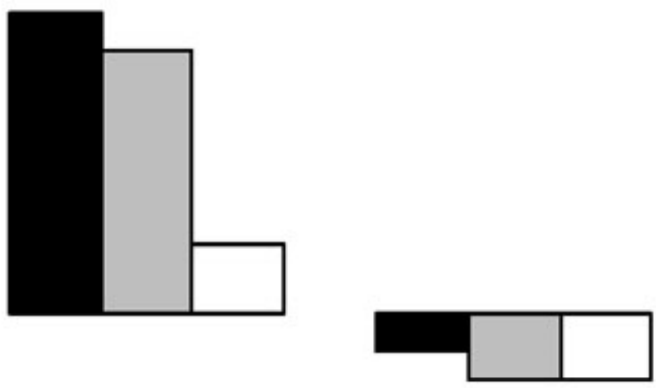

Mid

High 
FIG. G1. Estimated effects of insect herbivory on cactus population growth $\left(\lambda_{\text {insecticide }}-\lambda_{\text {control }}\right)$ partitioned among elevation zones and three interannual transitions for which we collected demographic data (2004-2005, 2005-2006, 2006-2007).

[Back to M079-005] 